BIS WORKING PAPERS

No. 13 - September 1990

MANUFACTURING SECTOR RESILIENCY TO ENERGY BOOMS:

Empirical Evidence from Norway, the Netherlands and the United Kingdom

by Michael M. Hutchison

BANK FOR INTERNATIONAL SETTLEMENTS

Monetary and Economic Department

BASLE 


\section{MANUFACTURING SECTOR RESILIENCY TO ENERGY BOOMS: \\ Empirical Evidence from Norway, the Netherlands and the United Kingdom*}

by

Michael M. Hutchison

September 1990

BANK FOR INTERNATIONAL SETTLEMENTS

Monetary and Economic Department

BASLE

* Comments on an earlier draft of this paper by Svein Andresen, Palle Andersen, Joe Bisignano and Ellen Meade are greatly appreciated. The views expressed do not necessarily represent those of the Bank for International Settlements. 



\section{CONTENTS}

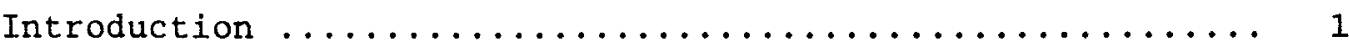

I Theory of Natural Resource Development

and "Deindustrialisation" $\ldots \ldots \ldots \ldots \ldots \ldots \ldots \ldots \ldots$

II Statistical Contours: Experiences of the Netherlands, Norway and the United Kingdom .................. 20

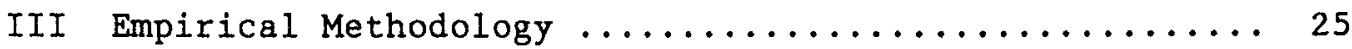

IV Empirical Results ...................... 32

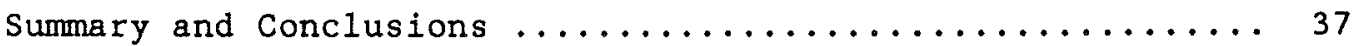

Appendix: Statistical Sources .................. 40

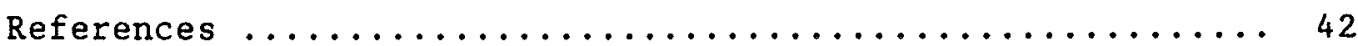




\section{Introduction}

The United Kingdom, the Netherlands and Norway share in common petroleum or natural gas based energy sectors which have come to play large roles in their economies. The discovery of the vast slochteren natural gas field in Groningen province in the Netherlands in 1959, and oil a decade later in the British and Norwegian sectors of the North Sea, not only represented large increases in the national wealth of these countries but also precipitated rapid growth in their energy sectors. Together with the sharp rise in energy prices during the 1970s, the development of oil and gas resources allowed these nations to move from positions of net energy importers to net exporters of energy for Norway and the United Kingdom, and greatly reduced dependence on energy imports in the case of the Netherlands. Government revenues from the energy sector also burgeoned.

Much of the policy discussion following the energy boom in these nations focused not on these new-found riches, however, but on the potential adverse effects of the booming energy sector on other sectors in the economy. Although the boom increased overall national wealth and improved the balance of payments, it was feared that some sectors would decline in a drawn-out and costly adjustment process. In particular, it was predicted that manufactures - to the extent that they were exposed to international competition - would contract, and adversely affect whole regions and major segments of the work force. This in turn raised concerns of national "deindustrialisation", partly because of the production and employment disruptions that restructuring the economy towards a larger energy sector entails and partly because of the presumption that long-term national growth potential is intimately tied to a strong industrial base. The concern is that allowing the industrial sector to decline will prevent the assimilation of technological progress which results from learning-by-doing manufacturing experience. ${ }^{1}$ That the export boom is based

1 See van Wijnbergen (1984) for a formalisation of this idea, and Neary and van Wijnbergen (1986c) for a broader discussion. The basic model assumes that technological progress takes place at a more rapid rate in manufacturing and to a large extent it is external to the firm (it creates externality effects). In these circumstances, there is a case 
upon exploitation of an exhaustible natural resource highlights fears associated with a shrinking manufacturing sector.

A natural resource based export boom with these adverse effects has been characterised as the "Dutch Disease." 2 This term is associated with the difficulties experienced by the Dutch manufacturing sector after the natural gas boom, hike in world energy prices and expansion of the gas-revenue financed government sector expansion in the Netherlands. Similar characterisations have been applied to the rich North Sea oil discoveries, booming oil exports, and associated decline of manufactures in the United Kingdom and Norway in the $1970 \mathrm{~s}^{3}$

Although a great deal of theoretical work has been directed at analysing the effects of oil and natural gas discoveries on the manufacturing sectors of these economies, relatively little formal statistical work has been applied to this problem. This is an important area of investigation because the size of the gross and net effects of an oil boom on the economy remains an unresolved empirical issue. The unresolved nature of this issue is best illustrated in the context of the United Kingdom. The first empirical work on this topic for the United Kingdom was undertaken by Forsyth and Kay (1980), where they estimate that North Sea oil had the net effect of lowering the manufacturing base by 6 percent, largely by causing a major real exchange rate appreciation. Chrystal (1984) also attributes the sharp appreciation of sterling in 1979

(Footnote Continued)

for subsidising manufacturing, whether or not it is threatened with being squeezed by another booming sector.

This common term for the problem does not seem entirely appropriate, as pointed out by the Economist magazine reporting on the Netherlands: "To refer to a vast, valuable energy resource as the source of a 'disease' sounds rather ungrateful." (1977).

3 Studies of the UK experience include Forsyth and Kay (1980, 1981), Bond and Knobl (1982), Bean (1987) and Chrystal (1984). Kremers (1986) and Ellman (1981) investigate the Dutch experience and Bjerkholt, et al. (1981) report aspects of the Norwegian experience. Similar analyses have been applied to numerous other countries in quite different circumstances. For example, snape (1977) considers the adverse effects on agriculture and manufacturers associated with the mineral development boom in Australia, Kamas (1986) considers the adverse effects on non-booming sectors associated with the coffee and illegal drug export boom in Columbia, and Forsyth and Nicholas (1983) have interpreted the consequences on Spanish industry of the inflow of American treasure in the sixteenth century in Dutch Disease terms. 
and the deterioration in the manufacturing sector in the United Kingdom to North Sea oil. In contrast, Niehans (1981) argues that the abrupt halt in monetary expansion in 1979 is the fundamental reason for sterling appreciation and output decline at that time, not the discovery and development of the North Sea oil resources. Similarly, Buiter and Miller (1981, 1983) attribute the problem to a contractionary monetary policy reinforced by fiscal consolidation. Although Bean (1987) finds that North Sea oil appreciated sterling by about 10 percent in the first half of the $1980 \mathrm{~s}$, his estimates indicate that there was net stimulative effect on manufacturing output from the development of oil sector.

In light of these wide divergences in empirical estimates for the United Kingdom, Niehans (1981) suggests that a study of the Norwegian experience with oil and natural gas might be instructive. A comparative statistical analysis of the three European economies most influenced by oil and natural gas is the objective of this study. We empirically assess whether the development of the oil and gas sectors systematically had adverse effects on the manufacturing sectors in the Netherlands, the United Kingdom and Norway. In particular, we address whether the manufacturing sectors in these nations are smaller than would otherwise be the case as a consequence of their oil and natural gas booms, and attempt to quantify whether the costs of adjustment are primarily short-term in nature or represent longer-term adjustment problems as well. In order to empirically assess the effects of energy booms in these nations, we control for the effects of restrictive monetary policies, as well as the worldwide rise in energy prices, which also may have played important roles in the deterioration of manufactures during these episodes. A comparative analysis of this nature should help to isolate the effects of energy booms from the effects of monetary policies and other factors in explaining the performance of manufactures and the sources of output fluctuations more generally.

Section I reviews theoretical predictions of a country experiencing a natural resource boom. This literature has two basic components, one of which has its analytical roots firmly grounded in "real" trade theory and the other has its analytical roots in open economy macroeconomic models. Within this context, two alternative explanations restrictive monetary policies and worldwide oil price hikes - for the decline in manufactures are discussed. Section II briefly summarises the 
country experiences of the Netherlands, Norway and the United Kingdom with oil and natural gas discoveries and development of their energy resources. In this section the stylised facts relating the natural resource discoveries to output developments in the non-energy sectors are identified, and statistics are presented on the sectoral composition of output in several other industrial countries - the United States, Japan, Germany and France - representing experiences not denominated by energy sector developments. This analysis is designed to shed light on whether the developments in the manufacturing sectors of our energy boom focus countries (the Netherlands, Norway, and the United Kingdom) have contrasted sharply with these other nations, particularly over a longer-term horizon. Section III presents the methodology for a more formal statistical analysis designed to shed light on the relationships between the energy sector and manufactures in these countries, as well as to identify other potential explanatory factors. Section IV presents the empirical results. A concluding section summarises the major findings of the analysis and draws some policy implications from the study. 
Theory of Natural Resource Development and "Deindustrialisation"

There are two quite distinct theoretical approaches to analysing the effects of natural resource discoveries on the economy. The first approach is grounded in traditional trade theory and focuses on several production sectors (energy, traditional tradables, and non-tradables) and factor markets (labour and capital), and is entirely "real" in emphasis in that it focuses on sectoral output composition, factor employment and relative price shifts, and abstracts from financial and monetary issues. The strength of this approach is its explicit treatment of the degree of factor mobility, relative factor intensities in production, and the pattern of real commodity demands. Moreover, explicit attention is given to sectoral detail and on the distinction between the primary commodity tradable good (the "booming" sector), other tradable goods (the "lagging" sector), and non-tradable goods (non-tradable services, construction, and so on). The second approach extends the standard open economy macro-economic model to account for the aggregate demand and monetary effects of a natural resource discovery. The focus in this literature is on goods and asset market interactions, and on the dynamics of adjustment.

The Basic Deindustrialisation Argument in the Trade Theoretic Context

The adaptation of basic trade models to theoretical analysis of natural resource booms has been undertaken by snape (1977), Corden and Neary (1982), and others. ${ }^{4}$ Snape tries to explain the effects of natural resource development on other traded goods in Australia, and Cordon and Neary focus on the effects of Britain's North Sea oil development on manufactures. The basic Corden and Neary model assumes three sectors, consisting of two tradable goods - a primary commodity (the "booming"

4 See Arndt (1988) for an extension of this framework incorporating a financial sector. 
energy sector, $\left.Y_{e}\right)$ and manufactures $\left(Y_{m}\right)$ - and the non-traded good $\left(Y_{n}\right)$. Two factors are assumed, labour (L) and capital (K). Labour is assumed mobile between sectors and capital is assumed sector specific in the short-run (fixed). No distortions are assumed to exist in either factor or commodity markets. This allows relative prices and wages to freely adjust, and assures full employment of resources. For simplicity, national output is equal to national expenditure (no trade imbalances) and the development of the natural resource is treated as a simple shift in its production given existing inputs. 5

Following Corden and Neary, the initial labour market and commodity market equilibrium positions are represented by points $A$ in Figures 1 and 2. In the labour market figure, Figure 1, the vertical axis measures the real wage ( $w$; the nominal wage deflated by the price of tradables, i.e. $W\left(P_{t}\right.$ ) and the total available labour supply is given by the horizontal axis $O_{n} O_{t}$. Labour input into non-traded goods is measured as the distance from $o_{n}$ and labour input into tradables (both energy and manufacturing) is measured as the distance from $o_{t}$. Demand for labour in each sector is a decreasing function of the wage rate relative to the price of that sector's output, and hence $L_{i}$ represents the labour demand schedules for the initial pre-boom equilibrium ( $i=m, t$ and $n$; $i . e$. manufacturing alone, both manufacturing and energy tradables and services). The labour market clearing point is at $A$, and wage rate $w_{0}$, where the initial total tradables and non-tradables labour supply schedules intersect.

The commodity market is represented by the salter diagram (Figure 2) of production possibilities between tradable goods (both manufactures and energy; shown on the vertical axis) and non-traded goods (shown on the horizontal axis). Since the terms of trade (relative price of energy and manufactures, $\left.P_{t}=P_{e} / P_{m}\right)$ is fixed in world markets, the two tradable goods may be aggregated into a composite good, $Y_{t}$. The initial production possibilities curve is $\mathrm{TN}$, and given the pattern of domestic demand (represented by the indifference curve, $I_{0}$ ), an equilibrium point is established at point $A$. The slope of the common tangent to $T N$ and $I_{0}$ at

5 Hicks neutral technological change, i.e. a shift in the production function such as that the ratio of marginal products of the two factors remain unchanged at a fixed capital-labour ratio. 

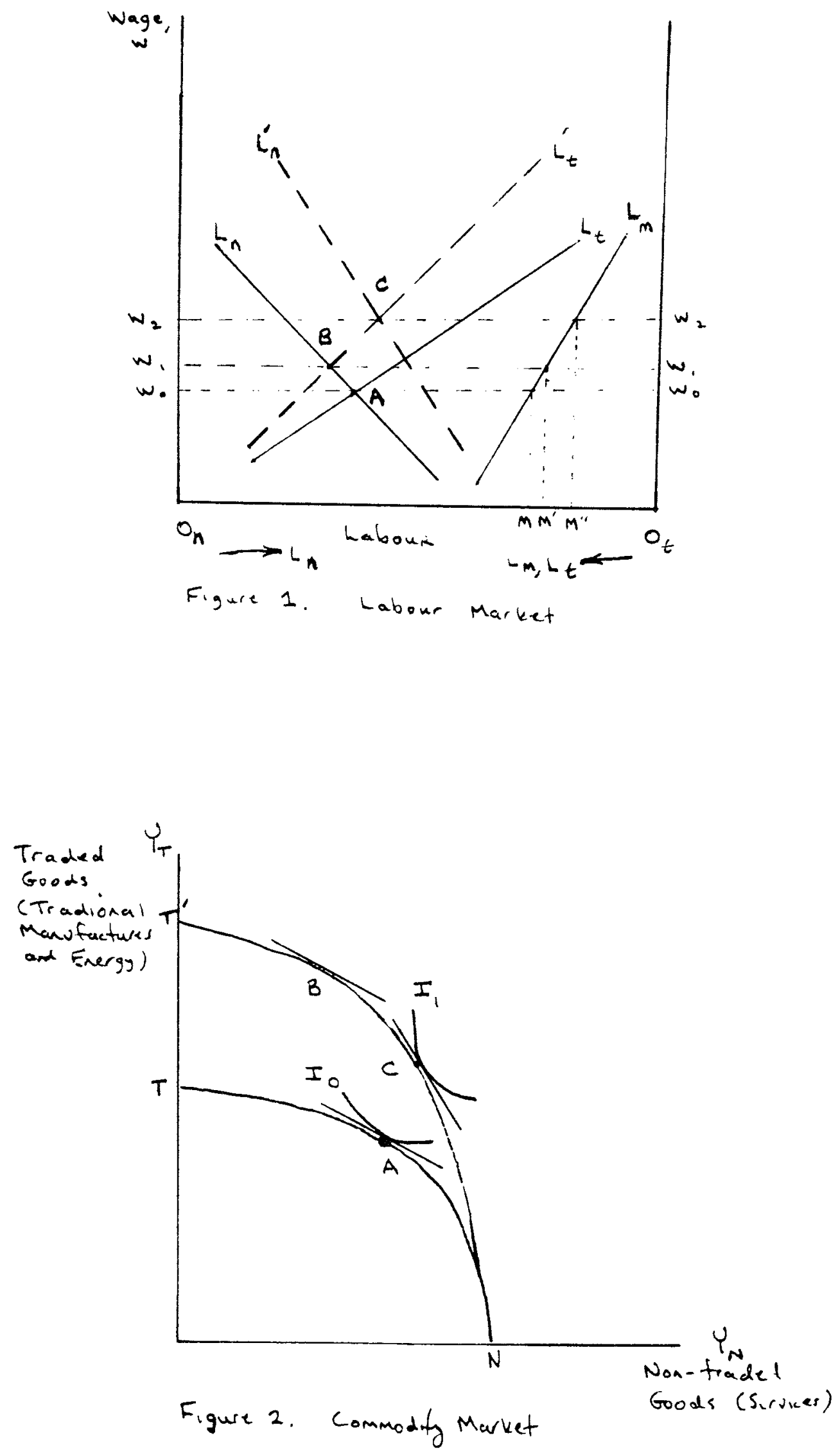
point $A$ is the relative price of services to tradable goods, i.e. the inverse of the initial real exchange rate $\left(q=P_{t} / P_{n}\right)$. The definition of the real exchange rate in this context is not arbitrary but follows from the nature of the model, i.e. the focus between internationally traded goods and the non-traded domestic good (services). Because of the small country assumption, the prices of the two tradable goods (manufacturing and petroleum) are fixed in world markets. Domestic conditions, and the domestic oil discovery in particular, may effect the price of services, but not the prices of manufactures or oil. Domestic conditions may therefore influence $q$, the relative price of services vis-à-vis the composite price of tradable goods, only by changing $P_{n}$. It is partly through this relative price that the effects of an oil boom are transmitted to the economy.

The energy boom is represented by a shift in the production possibility curve TN to T'N in Figure 2 - with unchanged factor inputs (as a first approximation), the economy is able to produce more energy but not services. It is traditional to consider first the effects on the economy if the real exchange rate were to remain constant, and thereby focus on the so-called "resource movement effect". ${ }^{6}$ This implies that the relative price of services, 1/q, in Figure 2 keeps the same slope and the labour demand schedule for services in Figure 1 remains unchanged. The energy sector's labour demand schedule shifts upward, shifting the aggregate tradables curve from $L_{t}$ to $L^{\prime}{ }_{t}$, as the resource boom acts analogously to a price increase by raising profitability and the demand for labour in the energy sector at a given wage rate. This puts upward pressure on the real wage, moves labour out of both manufacturing and services and into the energy sector, and $a$ new equilibrium represented by point $B$ in Figure 1 is reached. Since labour has moved from manufacturing to the energy sector in response to the higher real wage $\left(w_{1}\right)$, the resource movement effect leads to "direct deindustrialisation". Manufacturing output falls as its labour input declines from $O_{T} M$ to $O_{T} M^{\prime}$. In the commodity market this corresponds to point B.

6 The "resource movement" measures the extent to which a natural resource discovery draws resources out of other sectors, while the "spending effect" represents the consequences of a rise in wealth or income associated with the natural resource discovery. These effects will likely differ greatly depending upon the type of natural resource that is being exploited. 
As long as spending on services increases with income (services is a "normal good"), however, point B will reflect a position of excess demand for services output - higher production possibilities represent a rise in expenditure possibilities and causes a "spending effect" on the economy. Excess demand causes a rise in the relative price of services (i.e. an appreciation of the real exchange rate). In the commodity market Figure 2, a new equilibrium is established at point $C$, with its particular location depending on the pattern of aggregate demands. Services production will be greater than that represented at point B, but may be larger or less than that at the initial point $A$. In the labour market, the rise in the relative price of services shifts the labour demand schedule for services from $L_{n}$ to $L^{\prime}{ }_{n}$ and a new equilibrium (short and medium-term equilibrium in which labour is mobile, but capital is fixed) with the higher real wage $\mathrm{w}_{2}$ is established at point $C$. The additional rise in the real wage associated with the spending effect diverts yet more labour from the manufacturing sector (manufacturing faces rising costs; $P_{m}$ is fixed but $w$ increases) and hence brings about "indirect deindustrialisation". Both the resource movement and spending effects reinforce each other - labour in the manufacturing sector falls further from $O_{t} M^{\prime}$ to $o_{t} M^{\prime \prime}$ and manufacturing output correspondingly declines. 7

In order to explicitly relate the predictions of the trade model to our empirical analysis, we solve it algebraically in terms of the non-traded goods equilibrium condition (1) and the labour market equilibrium condition (2):

$$
\begin{aligned}
& Y_{n}(q, w)=C_{n}(q, \pi) \\
& ++ \\
& L_{n}(q, w)+L_{m}(w)+L_{-} \frac{(w, \alpha \pi)=\bar{L}}{-}+
\end{aligned}
$$

7 In the standard trade model, however, deindustrialisation following an energy boom need only be a short and medium-term phenomenon. In the Corden and Neary (1982) framework, for example, once capital is allowed to vary between sectors - a longer-term development as capital stocks adjust to differential rates of profitability - quite different output composition patterns may emerge. In particular, manufacturing output may rise or fall when both labour and capital is mobile between sectors, with the outcome depending upon the underlying production technologies and commodity demand elasticities. 
The real exchange rate (q), real wages (w), non-tradable goods supply $\left(Y_{n}\right)$ and the labour demand functions for each sector $\left(L_{n}, L_{m}, L_{e}\right)$ are as defined above. Non-tradable goods supply is negatively related to the real exchange rate and real wages. Note again that a rise in $q$ represents a real exchange rate depreciation (fall in the price of non-tradables relative to tradable goods). $C_{n}$ represents the domestic demand for non-tradables (by definition there is no foreign demand for the non-tradable good), and is positively related both to the real exchange rate and to the real income (wealth) associated with the oil boom (measured in terms of traded goods), $\pi$.

Aggregate labour supply is given fixed at $\tilde{L}$. In the two traded goods sectors, producing manufacturing and energy output respectively, output prices $\left(P_{m}\right.$ and $\left.P_{e}\right)$ are fixed and labour demand depends negatively on $w$, while in the non-traded goods sector it depends negatively on the real exchange rate relative to the real wage, $(q / w)$. In addition, some fraction of the energy boom itself may exert a direct influence on the demand for labour, represented by the inclusion of the parameter $\alpha$. The supply functions for manufactures and energy may be written analogously to the labour demand functions: $Y_{m}(w)$ and $Y_{e}(w, \alpha \pi)$, where total demand (domestic plus foreign) for these tradable goods is infinitely elastic at world determined prices.

The equilibrium of the model may therefore be solved in terms of the two endogenous variables, $q$ and $w$, and equations (1) and (2), from which the effects on manufacturing output may be derived. Specifically, we rewrite equations (1) and (2) in log linear form to give an explicit solution to the model (all variables expressed in natural logarithms, and al1 structural parameters are assumed positive):

$$
\begin{aligned}
& -a_{1} q-a_{1} w=a_{2} q+a_{3} \pi \\
& -b_{1} q-b_{1} w-b_{2} w-b_{3} w+b_{4}(\alpha \pi)=\bar{L}
\end{aligned}
$$

Solving in terms of $(q, w)$ gives:

$$
\begin{aligned}
& q=-\left[\left(a_{3}\left(b_{1}+b_{2}+b_{3}\right)+a_{1} b_{4} \alpha\right) / D_{0}\right] \pi+\left[a_{1} / D_{0}\right] \bar{L} \\
& w=\left[\left(a_{3} b_{1}+\left(a_{1}+a_{2}\right) b_{4} \alpha\right) / D_{0}\right] \pi-\left[\left(a_{1}+a_{2}\right) / D_{0}\right] \bar{L}
\end{aligned}
$$

where: $D_{0}=\left(a_{1}+a_{2}\right)\left(b_{1}+b_{2}+b_{3}\right)-a_{1} b_{1}>0$ 
The oil boom parameter unambiguously appreciates the real exchange rate $(\delta q / \delta \pi<0)$ and increases the real wage $(\delta w / \delta \pi>0)$. If there is no "resource movement effect", i.e. the development of the energy sector places no direct resource demands (no labour demand) on other sectors so that $\alpha=0$, then the energy sector is termed an "enclave" sector (see Corden, 1984; p. 363). In this circumstance, both the effect on the real exchange rate and on the real wage is less than otherwise, as only the "spending" effect is operative. 8

Focusing on the issue of deindustrialisation, consider the manufactures supply curve in log linear form:

$$
y_{m}=c_{0}+c_{1} \bar{p}_{m}-c_{2} w
$$

Substituting the reduced form real wage equation ( 6 ) into (7), and noting that $\bar{p}_{m}$ and $\bar{L}$ are given exogenously and assumed fixed for the moment, we derive the relationship between the energy boom $(\pi)$ and manufacturing output:

$$
\left.y_{m}=\left[c_{0}+c_{1} \bar{p}_{m}+\left(c_{2}\left(a_{1}+a_{2}\right) / D\right) \bar{L}\right]-c_{2}\left[a_{3} b_{1}+\left(a_{1}+a_{2}\right) b_{4} \alpha\right) / D\right] \pi
$$

Equation ( 8 ) states the basic result in terms of the underlying structural parameters in the model. The first term in brackets represents factors given exogenously and assumed fixed, and the second term focuses on the energy boom proxy, $\pi$. An energy boom leads to a decline in manufactures output in the short run, holding constant other factors (e.g. $\bar{p}_{m}$ and $\bar{L}$ ), and this effect is magnified the larger is the elasticity of manufactures supply with respect to real wages $\left(c_{2}\right)$, and the larger is the rise in the real wage. The real wage rise, in turn, is positively related to the magnitude of the "spending effect" $\left(a_{3}\right)$ in increasing the demand for domestic services and the "resource movement effect", i.e. the extent to

8 The resource movement effects applied to labour may also be exaggerated in the trade model analysis. To a large extent these sectors represent 'enclaves' separate from the rest of the economy, i.e. their demands on domestic resources may be small. The physical location of most of the production facilities in the North Sea illustrate this point. The capital/labour requirements of the oil and natural gas industries is quite high, and as a consequence the industry's absolute labour requirement is small in relation to its value added contribution to national output. 
which the energy boom demands labour resources for development of the sector $\left(b_{4} \alpha\right)$. Overall excess demand in the economy is attributable solely to the excess demand for services (oil and manufactures supplied domestically at the world price meet infinitely elastic demand) and causes a rise in services production and a decline in manufactures. International trade remains balanced as the rise in oil exports offset increased manufacturing imports .

This is the heart of the deindustrialisation debate. The boom in the natural resource sector is predicted to draw resources out of manufacturing and contract traditional industry through both a resource movement effect and a spending effect. The natural resource boom transmits its effects to the manufacturing sector through higher real wages, making production in traditional industry less competitive than previously. Assuming normal growth in the economy's productive capacity (the illustrative model assumes fixed factors of production), the general prediction is that an energy boom will lead to a smaller manufacturing sector than would otherwise be the case. ${ }^{9}$

\section{The Open Economy Macroeconomic Context}

Although the trade theoretic approach focuses explicit attention on the real commodity and factor market interactions induced by an energy boom, it abstracts from monetary and asset market effects as well as dynamics. This is the focus of the open economy macro-economic approach taken by Eastwood and Venerables (1982), Begg (1982), Buiter and Purvis (1983), and others. These theoretical papers extend the Dornbusch (1976) framework to analyse the effects of an energy boom. They follow Dornbusch in assuming perfect capital mobility (represented by open interest rate parity) and sluggish domestic price adjustment, and model the

9 To the extent that higher real wages and returns on investment are associated with an energy boom, international inflows of physical capital and labour may be anticipated. These inflows would tend to dampen the capital and labour "shortages" initially associated with the natural resource boom. This in turn lowers payments to these factors and works to restore the international competitive position of the manufacturing industry. See Corden (1984) for an analysis of both of these factors. 
natural resource discovery by its wealth effect directly on the demand for goods and money.

The strength of the natural resource boom wealth effect (proxied again by $\pi$ ) on money and goods demands in this model will dictate the particular dynamic path that the economy follows after a natural resource discovery, and the ultimate impact on the price level. ${ }^{10}$ The natural resource boom will unambiguously appreciate the exchange rate both in nominal and real terms in the short-term. Real appreciation of the exchange rate, now defined as the price of the composite domestic output relative to the price of the world composite output, will make traditional tradable goods uncompetitive and "crowd out" manufacturing in particular. The natural resource boom causes deindustrialisation, at least in the short-term, and the channel of transmission is via real exchange rate appreciation.

More specifically, the central features of these open economy macro-models may be described by an aggregate demand equation (9), a price adjustment equation (10), an open interest parity condition (11) and a money market equilibrium condition (12):

$$
\begin{aligned}
& \mathrm{y}=\beta_{1}\left(\mathrm{p}^{*}+\mathrm{s}-\mathrm{p}\right)+\pi \\
& \mathrm{p}=\beta_{2}\left(y-\bar{y}^{\mathrm{s}}\right) \\
& \mathrm{r}=\mathrm{r}^{*}+\mathrm{s} \\
& \mathrm{m}=\alpha_{1} \mathrm{p}+\left(1-\alpha_{1}\right) s+\alpha_{2}(\mathrm{a} \pi)-\alpha_{3} r
\end{aligned}
$$

where $y\left(\bar{y}^{s}\right)$ is demand (supply) of traditional domestic output (the aggregate of traditional tradables, $y_{m}$, and non-tradables, $\left.y_{n}\right), p\left(p^{*}\right)$ is the aggregate domestic (foreign) price level, $s$ is the nominal exchange rate (domestic currency price of foreign currency), $\pi$ is real income (wealth) associated with the natural resource sector, $r\left(r^{*}\right)$ is the domestic (foreign) interest rate, and $m$ is the domestic money supply. $\beta_{1}$,

10 The final effect on the nominal exchange rate is an unambiguous appreciation, but for the price level is unclear. The oil boom wealth effect increases both the demand for money and the demand for goods. The rise in money demand puts downward pressure on the price level, while the rise in goods demand puts upward pressure on the price level. The net effect is theoretically ambiguous in the absence of an accomodating monetary policy. 
$\beta_{2}, \quad \alpha_{1}, \quad \alpha_{2}$ and $\alpha_{3}$ represent parameter values and are positive. All variables except interest rates are expressed in logarithms. The circumflex denotes a proportional rate of change, and starred superscripts denote foreign variables. Time subscripts for all the variables are omitted and $p *$ is set to zero for notational simplicity.

The model has four endogenous variables ( $y, p, r$ and $s$ ) and five exogenous variables: the natural resource boom $(\pi)$, exogenous output supply $\left(\bar{y}^{s}\right)$, the foreign price level $\left(p^{*}\right)$, foreign interest rates $\left(r^{*}\right)$ and money $(m)$. Goods demand depends upon the real exchange rate $\left(q=p^{*}+s-p\right)$ and the income/wealth effects associated with development of the natural resource sector $(\pi)$.

Note that the real exchange rate is defined here as the price of the foreign composite output $\left(p^{*}\right)$, taken as exogenous, relative to the price of the domestic composite output (s - p). This is the conventional definition of the real exchange rate, and allows for imperfect substitutability between foreign and domestic products, and hence relative price fluctuations. Domestic price level changes are positively related to the extent of excess demand $(y-\bar{y})$. Capital mobility is assumed to equate domestic interest rates with the exchange rate adjusted returns abroad $(r+s)$. Finally, money demand is a function of the domestic consumption weighted price index (a weighted average of the domestic and foreign goods, expressed as $\alpha_{1} p+\left(1-\alpha_{1}\right)\left(p^{*}+s\right)$, income/wealth effects associated with the energy sector, and domestic interest rates.

Focusing on the real exchange rate, its stationary equilibrium value (no expected exchange rate or price level changes) is:

$$
\bar{q}=\left(y^{s}-\pi\right) / \beta_{1}
$$

A rise in the productive potential of the natural resource sector ( $(A)$ unambiguously appreciates the real exchange rate ( $\mathbf{s}-\hat{\mathrm{p}}$ is negative; i.e. the relative price of domestic goods increases) from one stationary equilibrium to another.

Although the dynamics of the adjustment process are more complicated than the simple comparative static steady state results, the real exchange rate also unambiguously appreciates in the short term following the energy boom because of the excess demand conditions created in both the goods market (equation (9)) and the money market (equation (12)). This is shown in Figure 3 . The phase diagram in the $(s, p)$ 


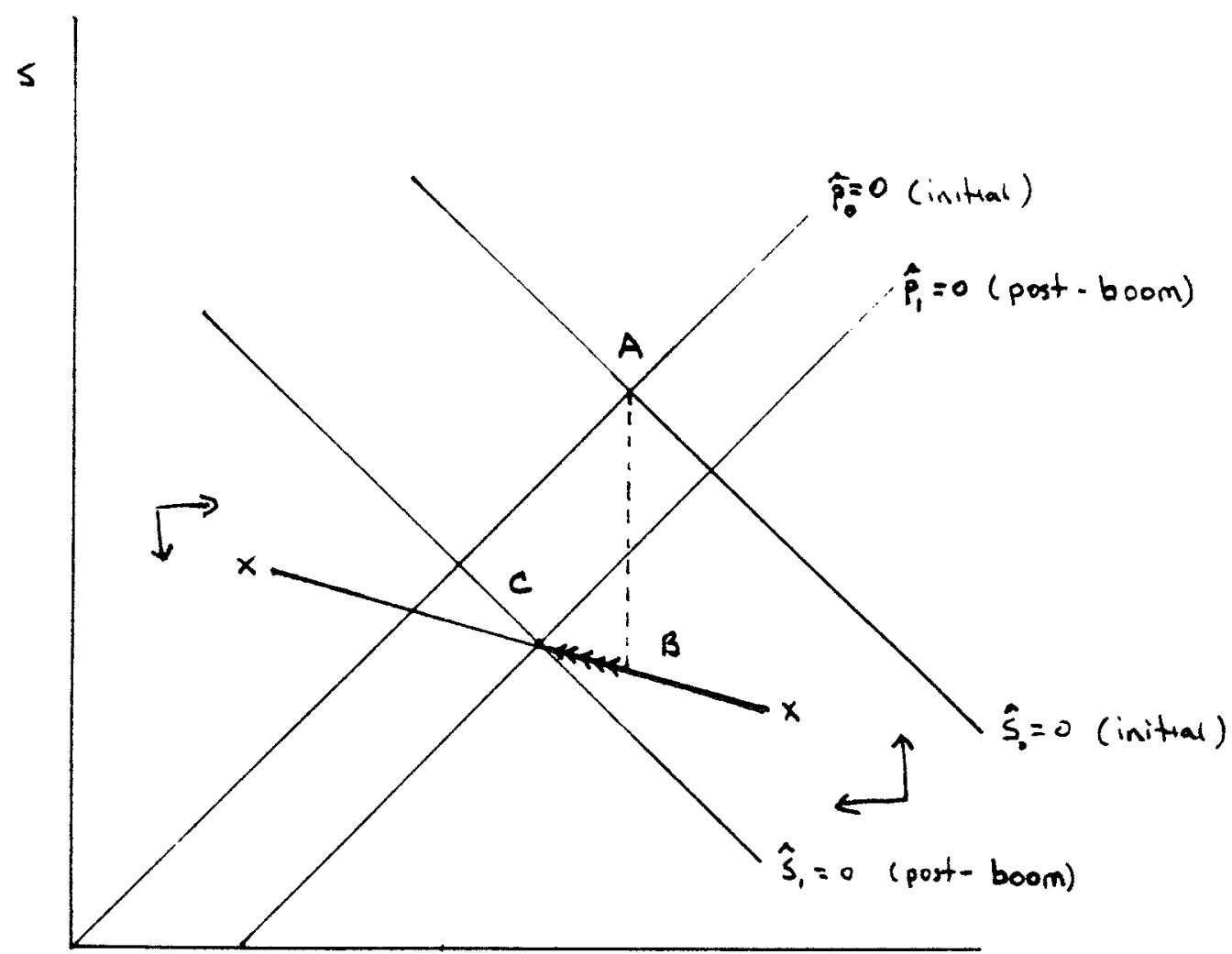

Figure 3. Effects of Energy Boom on Exchange Rated an Prices

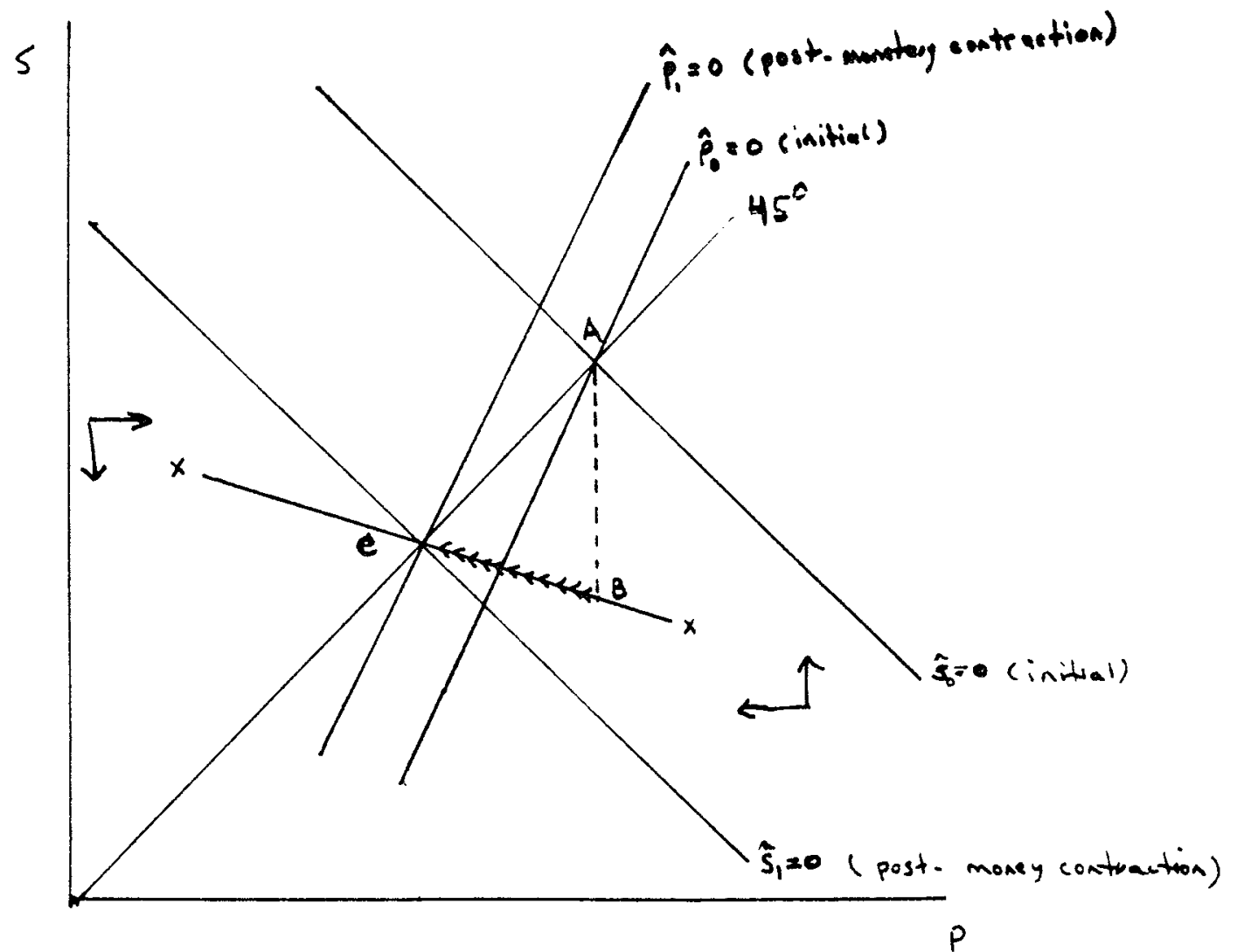

Figure 4. Effects of Monetary Contraction .. Exchange Reter and Prises 
space shows the $\hat{\mathrm{p}}=0$ locus corresponding to the goods market equilibrium conditions imbedded in equations (9) and (10), and the $s=0$ locus corresponding to the asset market equilibrium conditions imbedded in equations (11) and (12). Points above the $\hat{p}=0$ locus represent situations of excess goods demand where prices are rising, while below the locus there is excess goods supply and falling prices. Points above the $\mathbf{s}=0$ represent situations where domestic interest rates are above foreign interest rates and the exchange rate must be expected to depreciate (increase). Points below represent situations where domestic interest rates are below those abroad and the exchange rate is expected to appreciate (fall). The stable arm of the dynamic adjustment path (labelled $\mathrm{XX}$ ) must therefore be downward sloping.

The initial stationary equilibrium (no expected changes in prices or exchange rates) is represented in Figure 3 by point $A$ at the intersection of $\left(\hat{\mathrm{p}}_{0}, \hat{\mathrm{s}}_{0}\right)$. The natural resource boom has two effects in this model. First, it increases the demand for domestic output (equation (9)) and thereby shifts down the initial goods market equilibrium condition $\left(\hat{p}_{0}\right)$ to $\hat{p}_{1}$. Second, it increases the demand for money and thereby shifts down the initial asset market equilibrium condition $\left(s_{0}=0\right)$ to $s_{1}$. As noted above, the new stationary equilibrium of the economy involves a real appreciation of the exchange rate. This is accompanied through a nominal appreciation ( $f a l l$ in $s$ ), which is either supported by a rise in prices, or only partly offset by a fall in the price level. This is represented by point $C$ in the diagram.

The dynamics depend crucially on how quickly prices adjust to conditions of excess goods demand, captured by the parameter $\beta_{2}$. The standard assumption in this class of models, following Dornbusch (1976), is that prices are "sticky" (slow to adjust) while asset prices (exchange rates and nominal interest rates) adjust instantaneously, i.e. $0<\beta_{2}<\infty$. This generates the well-known "overshooting" result. Assuming this pattern of adjustment, the exchange rate would immediately jump from point $A$ to $B$ following an energy boom, and then follow the stable convergent path and gradually depreciate ( $s$ rises) towards point $C$ as prices gradually fall. The diagram is drawn for a situation where the money demand effect of the energy boom dominates the goods market effect in terms of the impact on prices. That is, prices are assumed to fall. It is also possible, however, that the goods market effect dominates and that prices rise. In this 
situation, the exchange rate would again jump to the stable convergent path and then continue to gradually appreciate ( $s$ falls further) together with the rise in the price level.

The intuition behind these results is straightforward. Taking the case represented in Figure 3, the energy boom causes both an excess demand for domestic goods and money. In the absence of immediate price adjustment, domestic interest rates rise to "choke off" excess demand and this causes a foreign capital inflow and an immediate appreciation of the exchange rate. As money market excess demand conditions gradually dissipate following downward price adjustments, interest rates gradually fall back to world levels and the exchange rate as a consequence depreciates.

The effect of the energy boom on output composition in the open economy macro-model is similar to that in the trade model, but in this instance the contractionary effect on manufactures (or, more generally, traditional tradables) is transmitted via real exchange rate appreciation. Real exchange rate appreciation associated with the oil boom changes the composition of output away from manufactures and towards non-tradable goods, i.e. the distribution of demand between manufactures. $\left(y_{m}\right)$ and non-tradable goods $\left(y_{n}\right)$ is negatively and positively related to real exchange rate movements, respectively. Tracing the factors which generate real exchange rate movements allow us to infer their effects on the manufacturing sector as well. In particular, in both the short term and the longer term an energy boom is predicted to appreciate the real exchange rate, and thereby contract manufactures.

It is noteworthy that either the private or the public sector may experience the wealth effects associated with a natural resource discovery, depending upon the allocation of property rights in this regard. If the government captures rents from the resource through taxation, there may be pressures to increase the scale of public goods. ${ }^{11}$ In the cases of the Netherlands, Norway and the United Kingdom, government rents from petroleum and natural gas production have been significant, and at least in the Netherlands and Norway, a rise in government sector expenditure financed by natural gas and oil have proven a major channel through which aggregate demand has increased. Kremers (1986), for example, emphasises that a

\footnotetext{
11 See Neary and Van Wijnbergen (1986) for a discussion of this issue.
} 
correct assessment of Dutch Disease type of developments in the Netherlands must take into account the "endogeneity of budgetary policy" (p. 125). This may be interpreted as a wealth effect, proxied by our $\pi$ variable, and in this model will cause appreciation of the exchange rate and a contraction of manufacturing.

\section{Alternative Explanations for Deindustrialisation}

Researchers have applied the basic Dutch Disease analysis to explain weak manufacturing performance in a number of episodes. ${ }^{12}$ In several cases, however, the deindustrialising experience also appears consistent with other potential explanations. Two main alternative explanations have been advanced - one view that attributes most of the decline to a temporary cyclical phenomenon associated with contractionary financial policies (Niehans, 1981; Buiter and Miller, 1981 and 1983), and a second view that attributes most of the decline in manufacturing to world-wide energy price hikes (Bruno and Sachs, 1982; Bean, 1987). ${ }^{13}$

Tight fiscal and monetary policies could be primarily responsible for cyclical contractions in the manufacturing sector, and this development may be simply coincident with an energy discovery. In the case of the United Kingdom, Niehans (1981) and Buiter and Miller (1981) argue that the decline in manufactures and the appreciation of sterling was primarily attributable to a monetary tightening during the early years of the

12 The number of papers supporting the Dutch Disease explanation for the decline in manufactures include, for the case of the United Kingdom, Forsyth and Kay (1980 and 1981), Corden (1981), Corden and Neary (1982), Kaldor (1981), and Eastwood and Venables (1982). Other researchers suggesting this explanation are Kremers (1986) and Ellman (1981) for the Netherlands. Bjerkholt et al. (1981) and Andresen (1983) apply the analysis to Norway. It is noteworthy, however, that Corden (1984) expresses some doubts about his earlier work: "The central argument that the simple Dutch Disease explanation for manufacturing decline does not apply to the UK seems quite convincing, in spite of Kay (1980) and others, including the present writer in earlier incarnations. One should note Niehans (1981) who seems to have shown that the severe UK appreciation of 1979 and 1980 can be explained mainly by a monetary squeeze, not Dutch Disease effects." (p. 376)

13 The debate has focused to a great extent around the experience of the United Kingdom rather than Norway or the Netherlands. 
Thatcher government. ${ }^{14}$ Buiter and Miller (1983) argue further that the adoption in the United Kingdom of targets for the public sector borrowing requirement starting with the 1980 budget produced a highly restrictive fiscal policy, exacerbating the fall in aggregate demand and drop in manufactures

This prediction is easily illustrated in the context of the open economy macroeconomic model, shown in Figure 4. The initial equilibrium is again represented in the phase diagram by point $A$ at the intersection of $\left(\hat{p}_{0}, \hat{s}_{0}\right)$. A monetary contraction lowers both the long-run equilibrium price level and nominal exchange rate (i.e. appreciates the nominal exchange rate). This is represented at point $C$, and falls along a $45^{\circ}$ line from the origin because the logarithmic change (percentage change) in prices is exactly matched in the longer-term by the change in the nominal exchange rate. This reflects the money neutrality characteristic of the model, which insures that the real exchange rate and structure of output is not affected in the long-run by monetary policies. ${ }^{15}$

As long as financial market prices (interest rates and exchange rates) adjust more rapidly than goods prices, however, a monetary contraction will appreciate the real exchange rate and contract the manufacturing sector in the short and medium-term. The monetary contraction creates situations of excess supply in the goods market and of excess demand in the money market. The former shifts the $\hat{p}=0$ locus to $\hat{p}_{1}$ and the latter shifts the $s=0$ locus to $s_{1}$. Because output prices adjust slowly, however, the economy does not move immediately to point $C$. Instead, real money balances fall initially in tandem with the contractionary monetary policy and cause domestic interest rates to rise above world levels. This in turn generates an immediate nominal and real appreciation of the exchange rate, represented by the move from point $A$ to point $B$ in Figure 4 .

14 This view is not necessarily indicated by the money aggregate chosen for targeting, however. The aggregate targeted, M3, consistently grew above its targeted path in 1980-82 period when manufacturing declined the most. Niehans (1981) suggests that $M 3$ provided a "distorted mirror" of monetary conditions and that the monetary base provides a better guide to policy.

15 This is seen by inspection of equation (13). Monetary aggregates do not enter into the long-run determination of the real exchange rate, $q$. 
Point $B$ lies along the stable arm of the dynamic adjustment path, $X x$. As prices gradually fall in response to the excess supply conditions in the goods market, domestic interest rates fall back to world levels and the exchange rate depreciates. This is represented by the movement from $B$ to $C$. This adjustment path is characterised by the well-known "overshooting" exchange rate phenomenon.

The similarities between the adjustment paths associated with an oil boom (Figure 3) and a monetary contraction (Figure 4) are noteworthy. Both are characterised by an initial real exchange rate appreciation and a consequent decline in manufacturing output. The primary differences 1 ie in the the longer run adjustments of the economy. In many instances, it may be difficult empirically to distinguish between the two adjustment paths, and hence to identify whether restrictive monetary policies or the influence of oil booms is responsible for a strong exchange rate and manufacturing sector weakness.

The other major alternative explanation for decline in the manufacturing base during some episodes has focused on the world price of energy, rather than simply development of domestic energy resources. Bruno and Sachs (1982), for example, emphasise that energy is an intermediate input into the manufacturing production process and develop a model which predicts a discrete decline in output and productivity immediately after an oil input price rise. This is followed by a longer-run slowdown in productivity growth, real wage growth, and capital accumulation - features which characterised the economy of the United Kingdom and most other countries in the late 1970 s and early 1980s. Moreover, Bruno and Sachs present some empirical tests and model simulation results which suggest that the rise in world energy prices played a significant role in the deterioration of the UK manufacturing sector during these years. Bean (1987) also finds that oil price shocks transmitted a significant contractionary influence on the manufacturing sector- an effect far outweighing any pure Dutch Disease effects associated with development of the petroleum sector. ${ }^{16}$

16 On a related point it is noteworthy that some of the short-term adverse consequences emphasised by the "Dutch Disease" literature may be exaggerated because they view manufacturing solely as a final output good and not as a capital good. In particular, the part of the 
This case may be illustrated within the context of either the trade theoretic approach or the open economy macroeconomic framework. In the trade theoretic framework, a rise in the price of energy may be modelled analogously to that of a sharp rise in the productivity of the oil/natural gas sector and with analogous results. ${ }^{17}$ In the open economy framework, the rise in the price of oil is modelled as an adverse supply shock which lowers potential output $\left(\bar{y}^{-s}\right)$. As shown in equation (13), this will have an analogous effect on the real exchange rate and manufacturing output as an energy boom. By lowering potential output, an adverse oil shock in this model will tend to appreciate the real exchange rate and force a contraction of manufacturing output.

Again a problem is faced in attempting to distinguish between two very similar adjustment paths: manufacturing sector adjustments to discovery and development of oil resources may be very similar to the adjustments associated with a world-wide rise in energy prices. Taken together with the stance of monetary policy, it is a difficult empirical issue to distinguish between these three potential influences on manufacturing output.

(Footnote Continued) domestic manufacturing sector involved in developing and maintaining the infrastructure supporting the oil and natural gas industries may well experience a boom associated with development of energy resources. Although some manufacturing industries may be adversely affected by the energy boom, other manufacturing industries are likely to be stimulated. The restructuring of the ship building industry to build off-shore oil rigs in Norway and the United Kingdom is only one example. 
II

\section{Statistical Contours: Natural Resource Booms and Manufacturing}

in the Netherlands, Norway and the United Kingdom

The stylised facts associated with the Dutch Disease analysis of energy booms are in many ways consistent with the experiences of the Netherlands, Norway and the United Kingdom in the 1970s. A simple version of the story runs along these lines: ( $i$ ) discovery and subsequent exploitation of the natural resource exerts a growing influences on aggregate economic activity and the structure of production; (ii) a sharp increase in the net energy balance followed by a decline in the non-energy trade balance; ${ }^{18}$ (iii) deterioration in the international competitive position, attributable both to real exchange rate appreciation and a rise in labour costs relative to major trading partners; (iv) a sharp increase in government revenues associated with oil rents, and a subsequent expansion of government employment; and, most important for our purposes, (v) stagnation or perhaps even contraction of the manufacturing sector.

Oil Production, Trade Balance and International Competitiveness

Table 1 shows total energy production in these countries (column 2) grew rapidly between 1970 and 1980, primarily due to natural gas and oil production increases. The Netherlands was the first to discover and begin exploiting these resources (natural gas was first discovered in the Netherlands in 1948, with the first major find the slochteren gas field in Groningen province in 1959), and its total energy output as a consequence grew in the latter 1960s. The 1970s saw the largest expansion, however, during which time energy production in the Netherlands grew six-fold. Largely due to conservation policies, energy output declined during the first half of the 1980 s.

18 Initially the balance of payments may deteriorate with the discovery of oil. A rise in domestic consumption and investment spending, and in the demand for imported investment goods associated with oil exploitation in particular, may increase imports several years before oil production begins. 
Table 1

Energy and non-energy balances of trade Norway, the Netherlands and the United Kingdom

\begin{tabular}{|c|c|c|c|c|c|}
\hline & \multicolumn{2}{|c|}{$\begin{array}{l}\text { Volume terms } \\
\text { (millions of tons of oil } \\
\text { equivalent) }\end{array}$} & \multicolumn{3}{|c|}{$\begin{array}{c}\text { Trade balances } \\
\text { (current L'S dollar value) } \\
\text { (in millions) }\end{array}$} \\
\hline & $\begin{array}{l}\text { Net energy } \\
\text { balance }\end{array}$ & $\begin{array}{l}\text { Memo: Total } \\
\text { energy } \\
\text { production }\end{array}$ & $\begin{array}{l}\text { Energy } \\
\text { balance }\end{array}$ & $\begin{array}{l}\text { Aon-energy } \\
\text { balance }\end{array}$ & $\begin{array}{l}\text { Overall } \\
\text { balance }\end{array}$ \\
\hline \multicolumn{6}{|c|}{ Norway } \\
\hline 1960 & - 4.29 & 4.97 & $\therefore A$ & $\mathrm{NA}$ & $\mathrm{NA}$ \\
\hline 1965 & $\begin{array}{l}-\quad 5.37\end{array}$ & 7.72 & $\therefore A$ & $\mathrm{NA}$ & $\mathrm{NA}$ \\
\hline 1970 & $\begin{array}{l}-\quad 9.39\end{array}$ & 9.00 & 10 & $-\quad 1,129$ & - 1,139 \\
\hline 1975 & 1.35 & 21.39 & $\begin{array}{l}-42 \\
-\quad 4\end{array}$ & - $\quad 3,313$ & - 3,354 \\
\hline 1980 & 36.34 & 61.18 & 8,214 & - $\quad 7,015$ & 1,199 \\
\hline 1985 & 52.15 & 78.71 & 9,795 & - $\quad 5,938$ & 3,858 \\
\hline $1987-8^{*}$ & 65.08 & 93.85 & 7,324 & - $\quad 6,216$ & 1,107 \\
\hline \multicolumn{6}{|c|}{ Netherlands } \\
\hline 1960 & - 13,84 & 11.21 & $\therefore A$ & $\mathrm{NA}$ & $\therefore A$ \\
\hline 1965 & - 25.02 & 12.03 & $\therefore A$ & $\mathrm{NA}$ & $N A$ \\
\hline 1970 & - $\quad 30.32$ & 29.67 & 81 & 819 & 900 \\
\hline 1975 & 2.98 & 72.52 & . 714 & 1,613 & 899 \\
\hline 1980 & $\begin{array}{l}-\quad 2.89 \\
\end{array}$ & 73.00 & $-2,678$ & 1,269 & - $\quad 1,409$ \\
\hline 1985 & $\begin{array}{l}-\quad 2.67\end{array}$ & 67.38 & 202 & 5,256 & 5,458 \\
\hline $1987-8^{*}$ & - 11.03 & 62.90 & $\quad 790$ & 3.838 & 8,048 \\
\hline \multicolumn{6}{|c|}{ United Kingdom } \\
\hline 1960 & -47.33 & 116.13 & $\therefore A$ & $\mathrm{NA}$ & NA \\
\hline 1965 & -73.85 & 115.57 & $\therefore A$ & $\therefore A$ & $\mathrm{NA}$ \\
\hline 1970 & -104.89 & 101.85 & $\cdot 1,188$ & 1,155 & 34 \\
\hline 1975 & - 92.66 & 115.09 & 6,804 & 433 & - 7,237 \\
\hline 1980 & -12.48 & 197.69 & 717 & 2,436 & 3,153 \\
\hline 1985 & 32.20 & 236.05 & 10,502 & - 13,543 & - 3,041 \\
\hline $1987-8^{*}$ & 33.36 & 240.65 & 4,965 & $-42,067$ & - 37,102 \\
\hline
\end{tabular}

* 1987 figures for volume, energy balance and production figures, 1988 for balance-ofpayments statistics.

Sources: Net energy balance and production in volume terms (mtoe) is from OECD Energy Balances of OECD Countries, $1970-85$ and 1986-7 editions.

Balance-of-Payments sources: LK - CSO Pink Book. Table 2.3.

Vetheriands - De Nederlandsche Bank Annual Report, Table 6.2.

Norway - CBS of Norway, Monthly Bulletin. Table 69. 
In the case of the United Kingdom, exploration in the 1960s had revealed significant reserves of oil in the North Sea but most of these fields were not profitable at pre-1974 oil prices. Although there was still no crude oil production in the United Kingdom up until the first oil shock in 1973, this changed dramatically with the quadrupling of oil prices which spurred rapid development of the North sea fields. Similar to the experience of the United Kingdom, crude petroleum production in Norway only became a significant factor in total production in the mid-1970s. In Norway, natural gas has also been an important foreign exchange earner since becoming an export product in 1978. Between 1970 and 1987 total energy production in Norway grew almost ten-fold, and more than doubled in the United Kingdom.

In tandem with production increases in these nations, net energy balance positions also improved. By the mid-1970s, Norway and the Netherlands had moved from substantial net energy importers to self-sufficiency and net positive export positions in energy. This occurred in the United Kingdom as well by the early 1980s. Improvements in the overall balance of payments positions mirrored to some extent the nominal energy balance improvement up until 1986.

An apparent decline in the international competitiveness of other sectors of the economy is suggested by the deterioration in the non-energy component of the trade balance, however, at least in the cases of Norway and the United Kingdom. This is indicated as well by evidence that expansion of the oil and natural gas sector of the economy may be related to several episodes of particularly rapid domestic labour cost increases. Chart 1 shows the growth in energy production mapped together with a measure of the real exchange rate reflecting relative costs, i.e. domestic unit labour costs relative to the exchange rate adjusted unit labour costs of the nation's major trading partners. Rapid expansion of the energy sector in its initial stages appears to be a source of both rapid wage growth and exchange rate appreciation.

On the wage side, a body of institutional evidence in the Netherlands and Norway suggests that productivity increases in the energy sector worked to raise labour incomes in all sectors via the centralised system of pay determination (OECD, 1983). Kremer (1986) notes, for example, that productivity in the natural gas sector influenced the aggregate indicator of labour productivity used in centralised wage negotiations. 
Chart 1

THE ENERGY SECTOR AND REAL EFFECTIVE EXCHANGE RATES Indices: $1975=100$
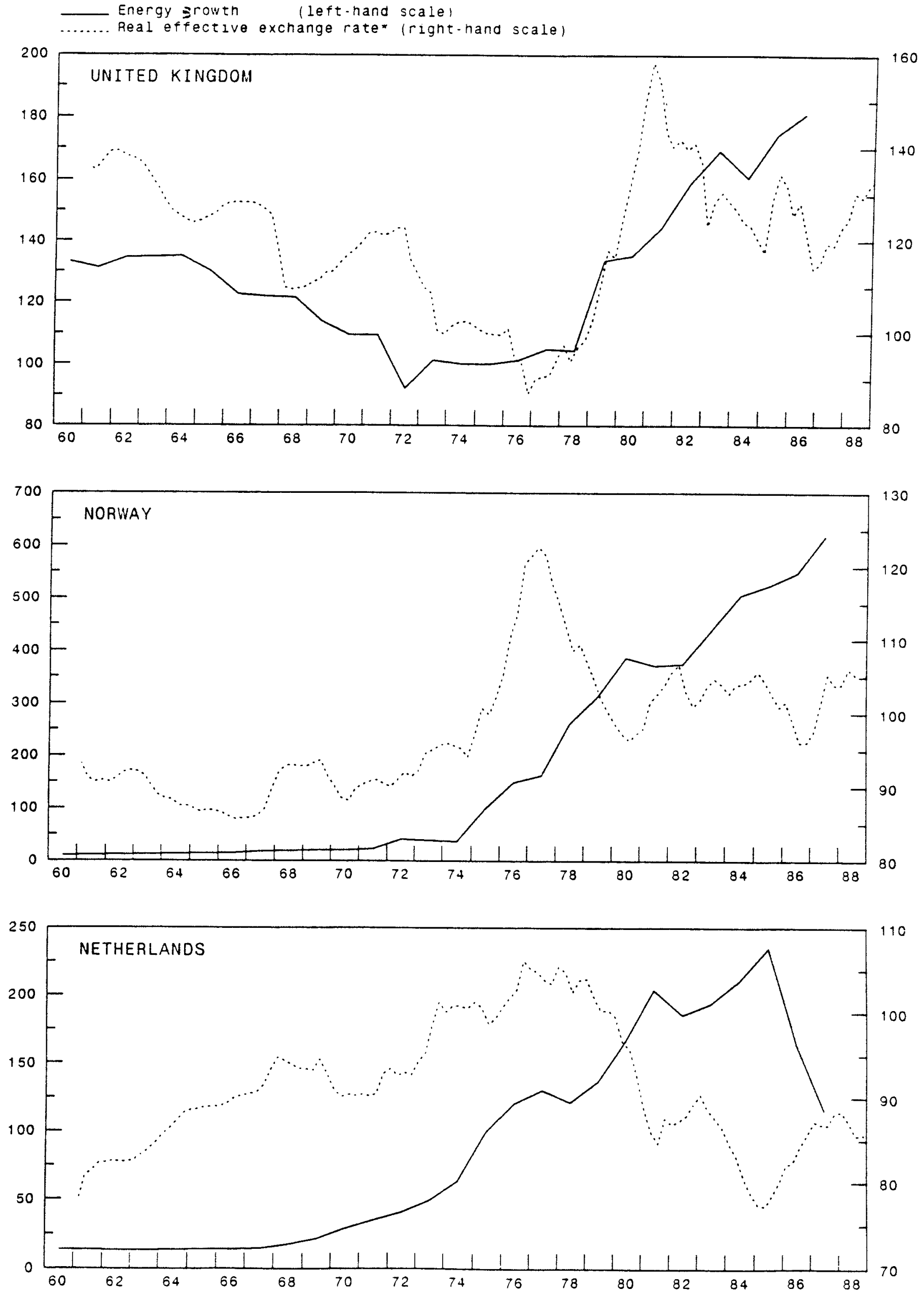
This pattern is true in the Netherlands and Norway despite the relatively small numbers directly employed in this industry. In Norway, for example, only 9300 people were employed in oil production and drilling in 1985. At the same time, the surge in government receipts from gas and oil allowed expansion of the government sector employment and was a major stimulus to aggregate demand and wage pressures (OECD, 1987). Again, the dependence of the government sector on oil is most pronounced in Norway. At its peak in 1985, oil revenues represented almost 20 percent of the total general government budget.

\section{Sectoral Output Shares}

The growth of the natural resource sector relative to the size of the economy has been clearly apparent in the Netherlands, and nothing short of dramatic in Norway. Its relative importance is less in the United Kingdom, but is also noteworthy in that this expansion reversed a long trend decline in total energy production (primarily associated with the secular decline of the coal industry). Charts 2 - 4 show the share of the energy sector (represented as total mining and quarrying) as a percentage of total gross domestic product, together with the shares represented by manufactures, services, and other sectors. The charts show both constant price and current price shares except for the Netherlands where only current price data are available on a comparable basis.

From virtually zero at the beginning of the 1960s, and still only a marginal factor until the early 1970s, the share of the oil/natural gas sector in Norwegian nominal GDP grew rapidly from the mid-1970s until the early 1980s, until peaking at close to 20 percent in 1985. Although the nominal share declined sharply in 1986 and 1987, following the collapse of oil prices, in constant price terms the energy sector has maintained a steady 20 percent real GDP share. Similar but less dramatic patterns are identifiable for the Netherlands and the United Kingdom.

A decline in the share of manufacturing value added has been in large measure the reverse image of the gain in the share of energy, however. This highlights the concern that the two are causally related and that manufacturing is being "crowded out". The relative decline in manufactures is brought out most vividly by a comparison of the growth patterns of the energy, manufacturing and service sectors in Norway and the United Kingdom in constant price terms, and relative to a common base year. 
Chart 2

GDP BY SECTOR: NORWAY

$\square$ Energ:

$Z Z C$ llanufacturing

EozZd Services

AT CURRENT PRICES, AS A PERCENTAGE OF GDP

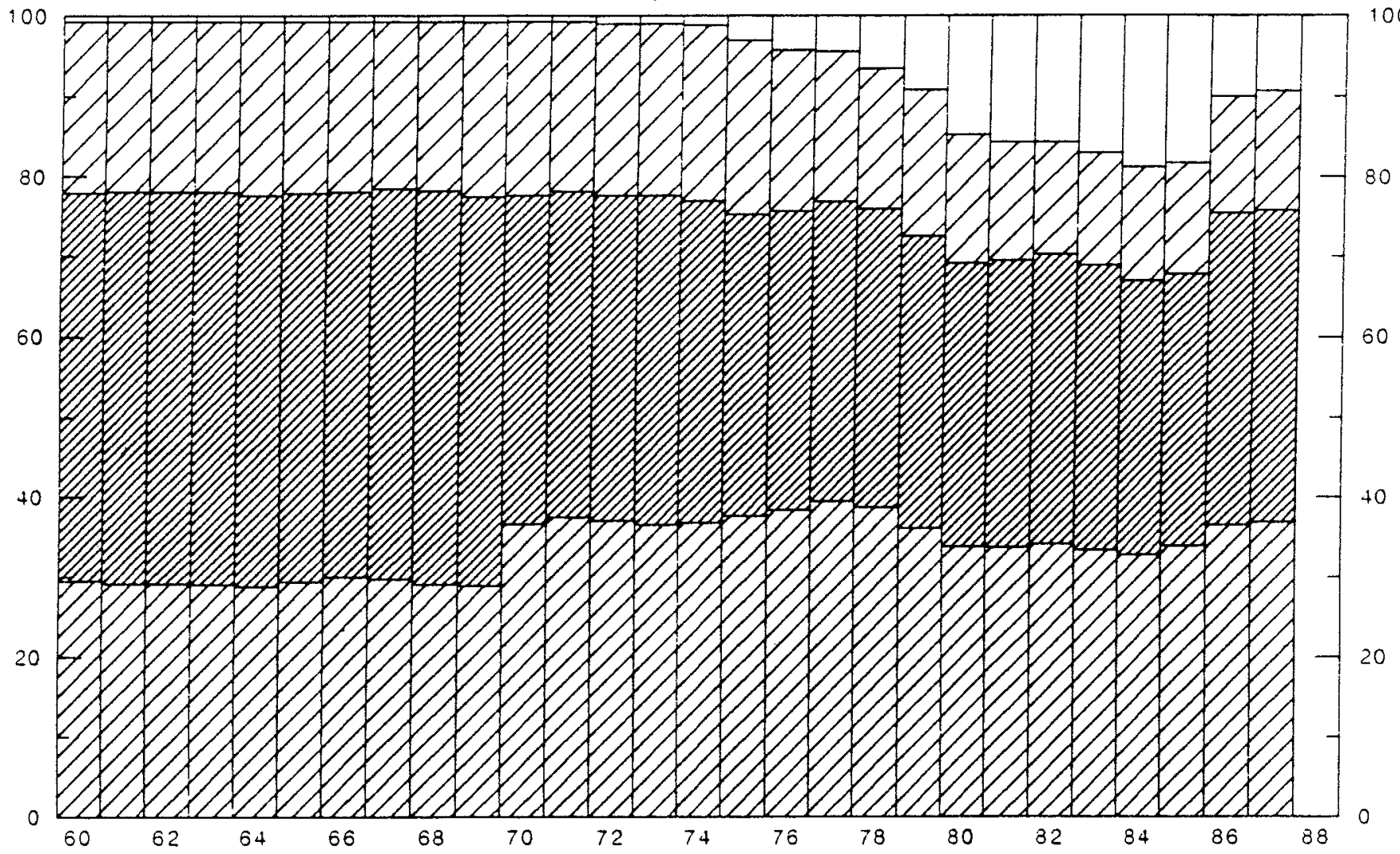

AT CONSTANT PRICES, AS A PERCENTAGE OF GDP

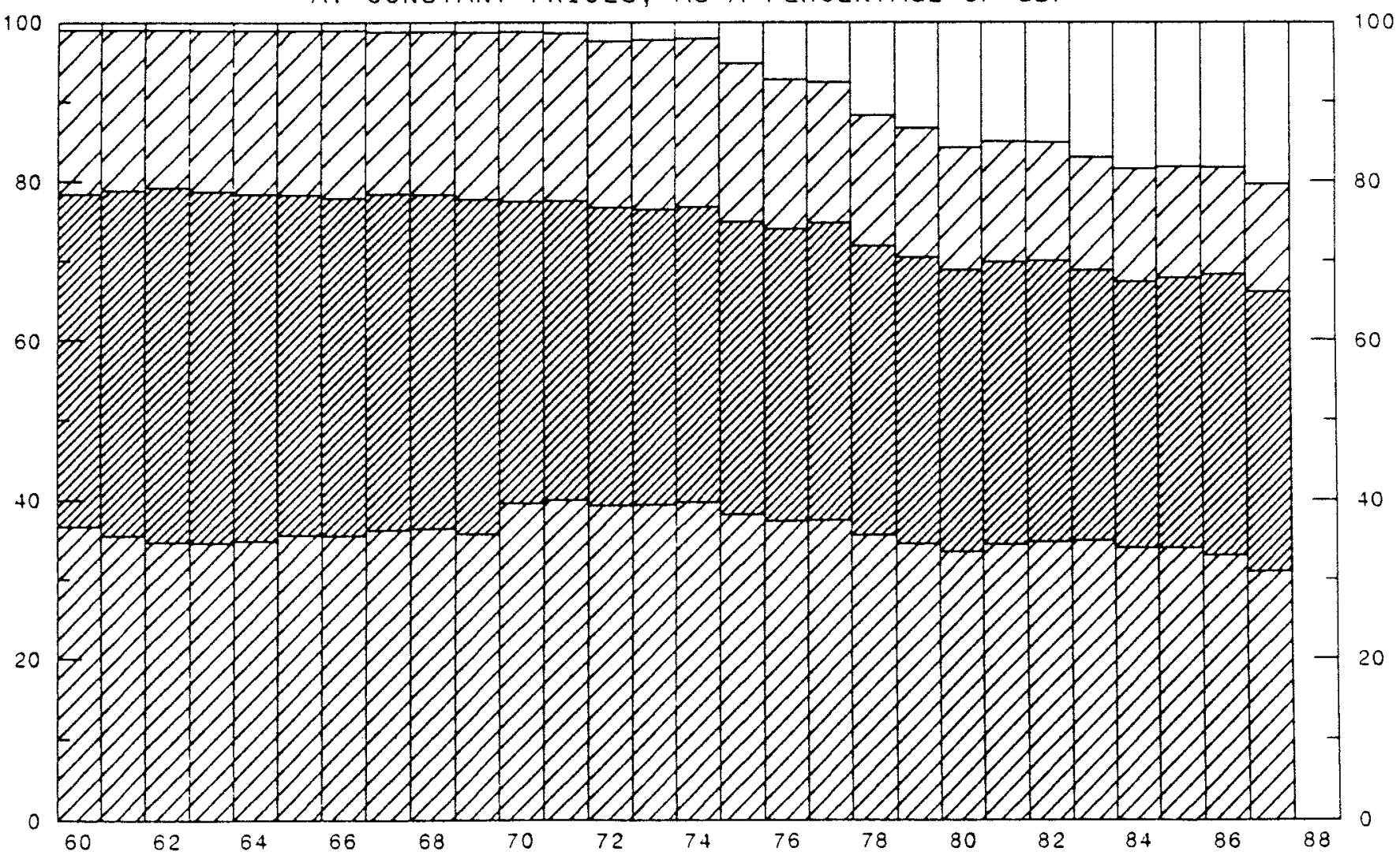


Chart 3

GDP BY SECTOR: NETHERLANDS

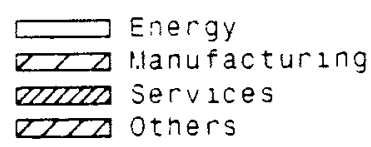

AT CURRENT PRICES, AS A PERCENTAGE OF GDP

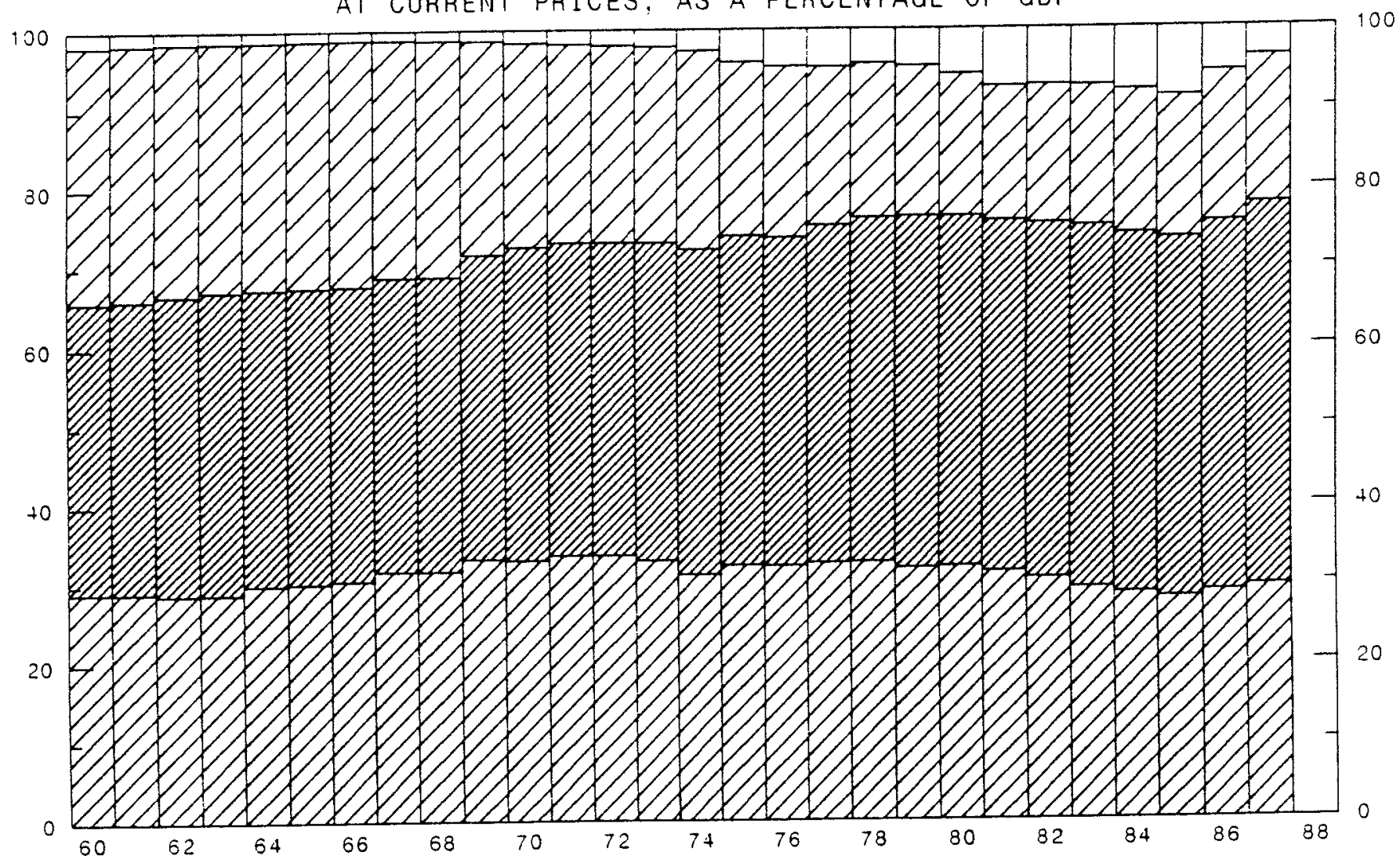


Chart 4

GDP BY SECTOR: UNITED KINGDOM

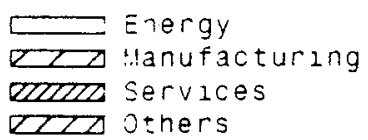

AT CURRENT PRICES, AS A PERCENTAGE OF GDP

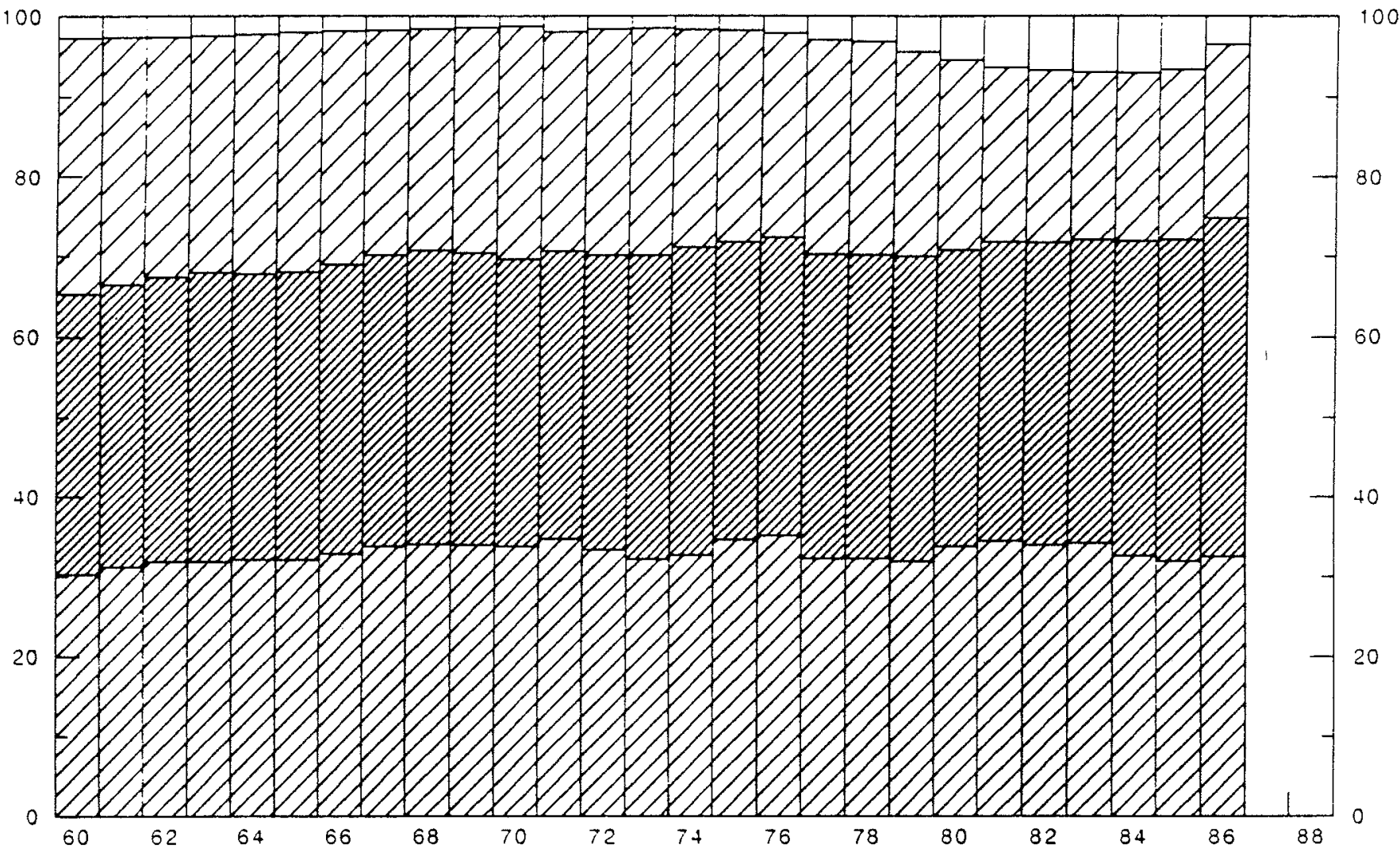

AT CONSTANT PRICES, AS A PERCENTAGE OF GDP

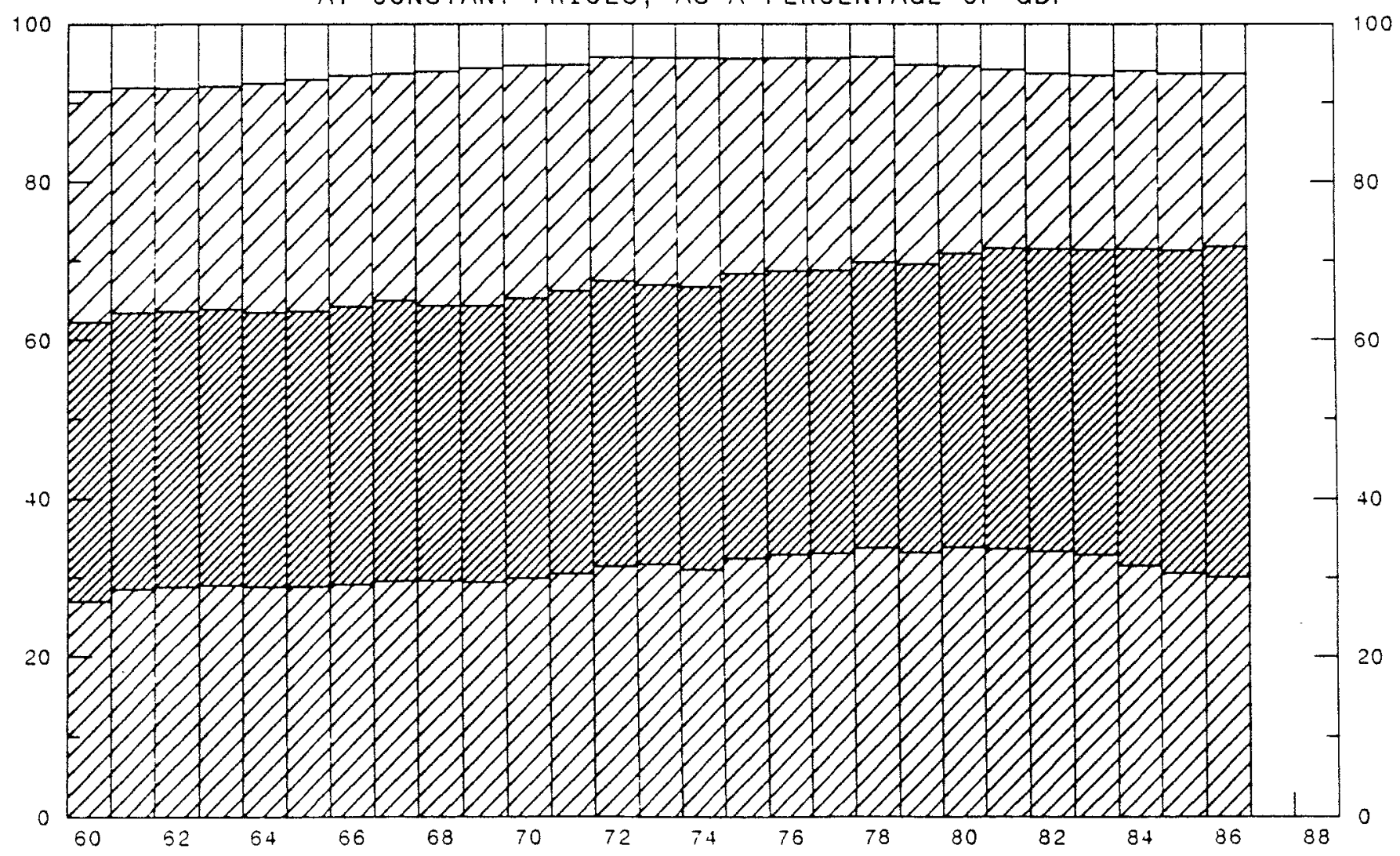


Manufacturing output (constant price value added) in Norway has been virtually stagnant since its peak in 1974, growing only around 4 percent over a 15 year period (Chart 5). This stands in sharp contrast to the rapid growth in the energy sector and the steady rise in services. For the United Kingdom, a similar but more volatile pattern emerged (Chart 6). Despite strong growth in manufacturing output since 1981, the contraction during the latter 1970s was so large that present production levels have not yet reached the peak established in 1973.

The rise in the energy sector has been dramatic since 1978 and, similar to Norway, a secular rise in services in the United Kingdom is also a dominating characteristic of the production profile. Manufacturing in the Netherlands, in contrast, has proved much more robust than either Norway or the United Kingdom. From the level reached before the cyclical downturn in 1974, the volume index of manufacturing production in the Netherlands has increased around 30 percent (end of 1989). To the extent that manufacturing robustness is an indication of the Dutch Disease, it appears that the Dutch economy has suffered its consequences less than the economies of either Norway or the United Kingdom.

These descriptive statistics are broadly consistent with the predictions of the Dutch Disease theory, although somewhat less so in the case of the Netherlands. Moreover, the statistics may understate the degree of manufacturing "crowding out" and loss in international competitiveness in Norway and the Netherlands. One reason is that government policies have been used to maintain traditional manufactures. This is particularly evident in Norway where "full employment" is an important policy objective, and a significant part of oil revenues have allowed increased business sector subsidy. ${ }^{19}$ Also, aggregate figures mask some major restructuring within the manufacturing sector. Some traditional industries have fared much worse than average, while others have been buoyed by the oil and gas industries. In Norway, for example, 50 to 60 percent of orders from the oil sector have been placed with domestic manufactures in some years. This has imparted a significant net stimulus to certain segments of the manufacturing sector. 
Chart 5

GDP AND ITS COMPONENTS: NORWAY

IN BILLIONS OF (CONSTANT) NATIONAL CURRENCY

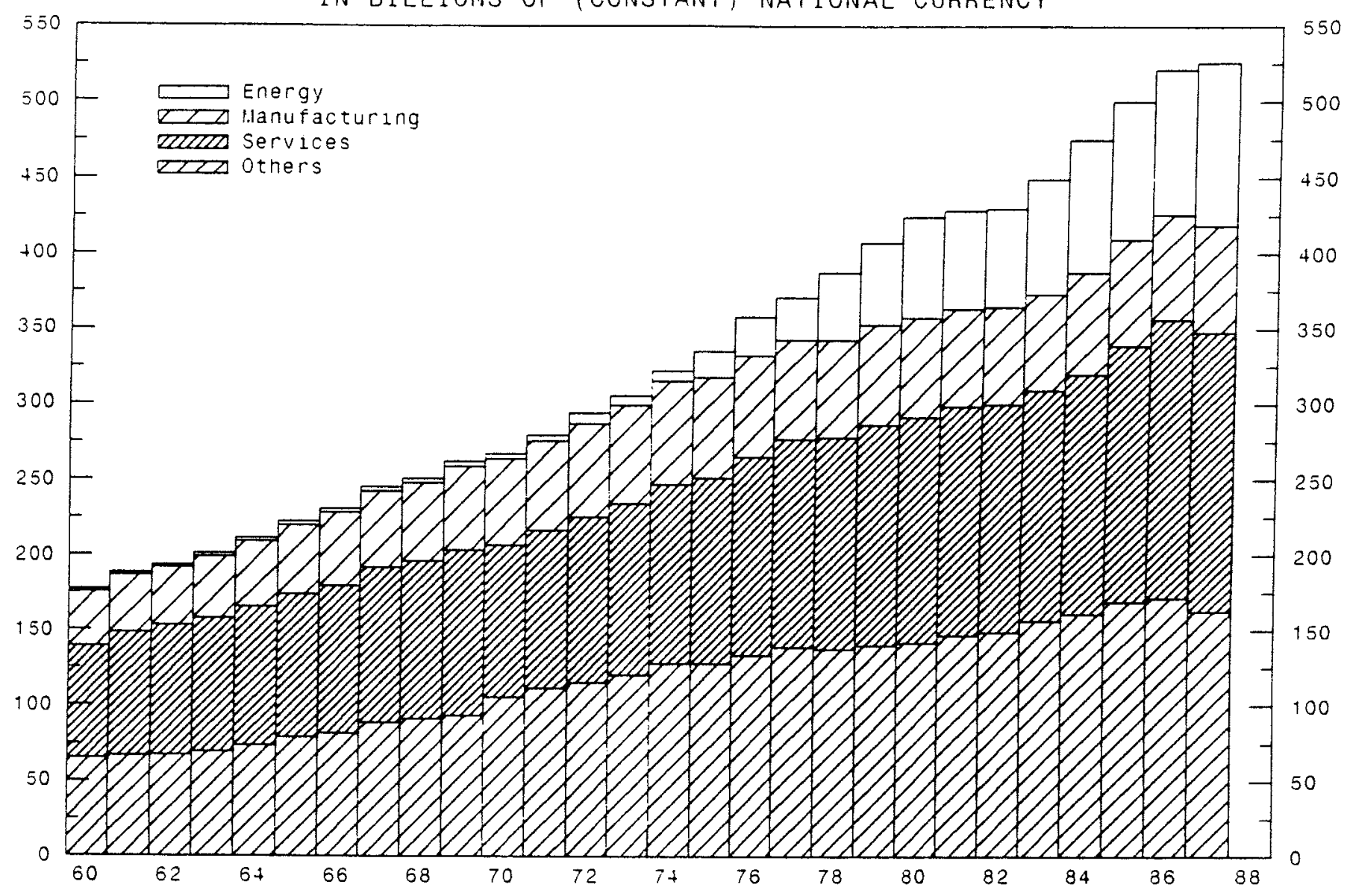

INDEX $: 1975=100$, AT CONSTANT PRICES

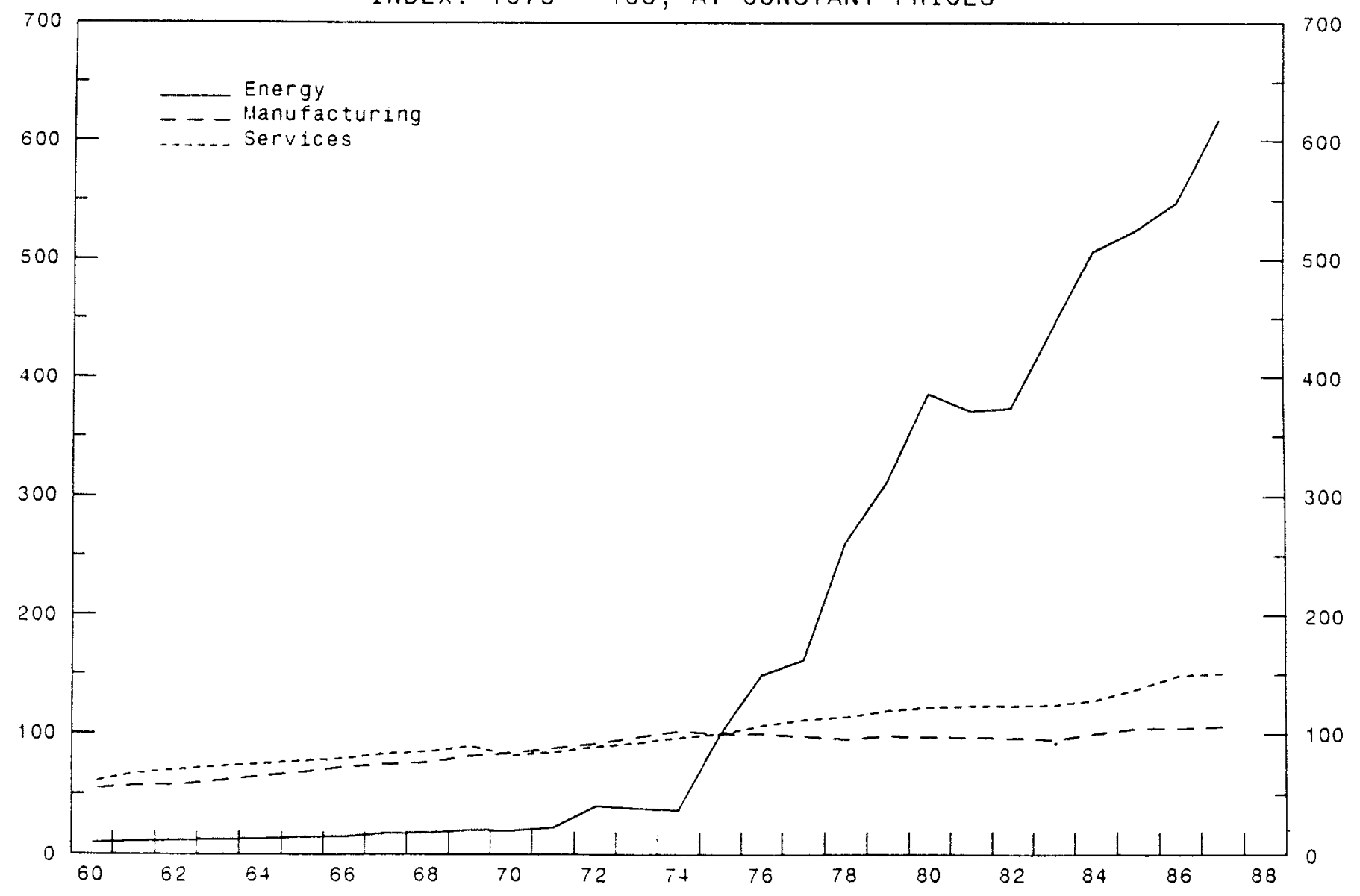




\section{$-23 b-$ \\ Chart 6}

GDP AND ITS CONPONENTS: UNITED KINGDOM

IN BILLIONS OF (CONSTANT) NATIONAL CURRENCY

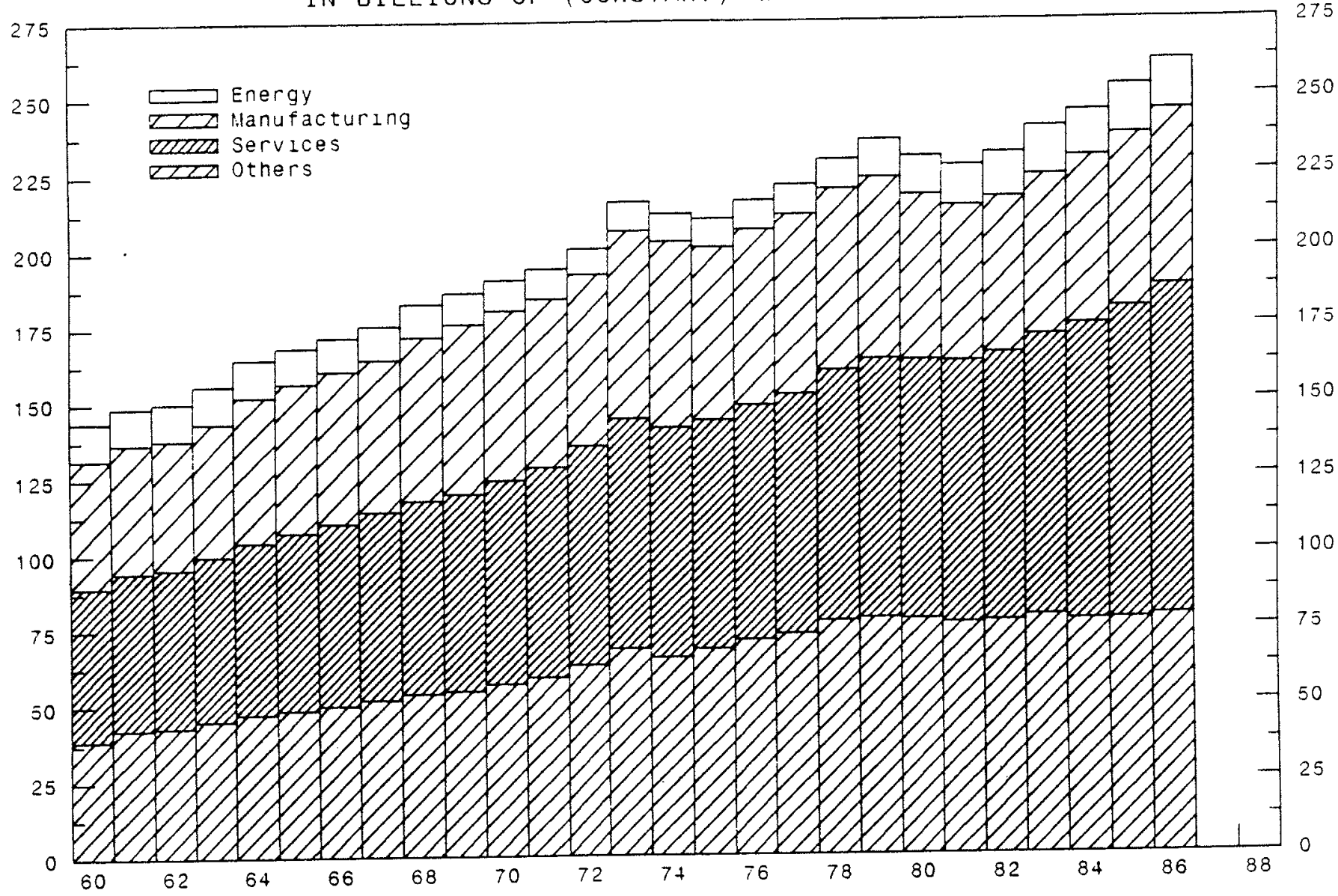

INDEX: $1960=100$, AT CONSTANT PRICES

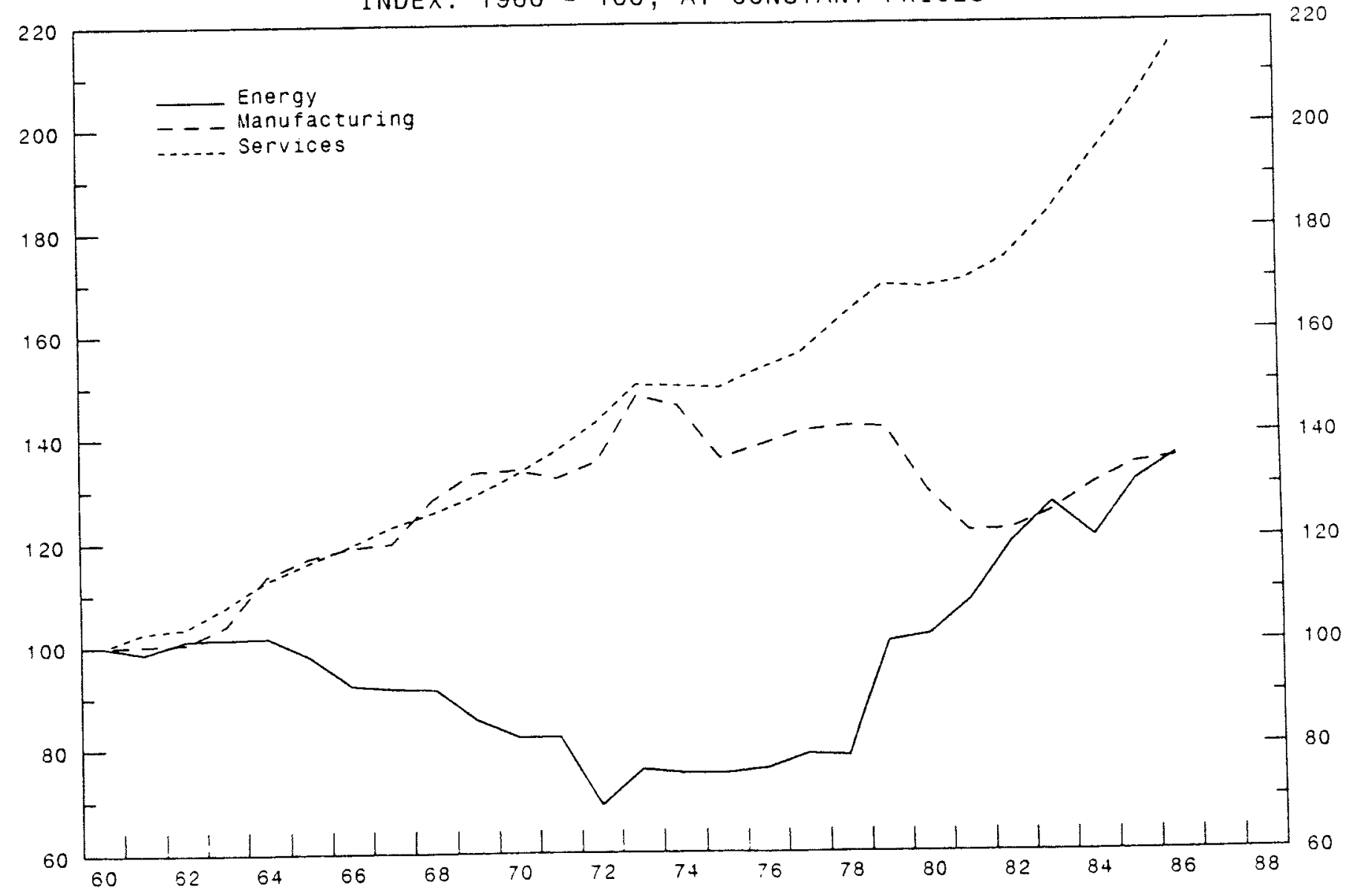


International Comparisons of Output Shares

Some insights are gained by placing these developments in a broader international perspective. Charts 7 and 8 show energy and manufacturing developments, respectively, for the three focus countries and four comparison countries not dominated by energy booms - the United States, Japan, Germany and France. The charts show the percentage of these two sectors in total output, both in constant and current price terms, relative to a constant base year. This draws attention to longer-term share change trends, and abstracts from structural differences between countries in share levels.

The energy share patterns shown in Chart 7 are not unexpected. In constant price terms they show uninterrupted declines of the value added share of energy in total output for all of the comparison countries. This stands in contrast to the rising shares in our focus countries since the mid-1970s. In current price terms, the declining trend was interrupted by the sharp rise in oil prices of the 1970 s which increased nominal shares for the comparison countries, particularly in the United States. The nominal share gains were much larger of course in the Netherlands, Norway and the United Kingdom.

More interesting patterns are identifiable for the manufacturing industry, shown in Chart 8 . Nominal manufacturing shares generally have fallen quite systematically over most of the three decade period for every country in the sample. The only exception to this trend is a period in the late 1960 s and early 1970 s when the shares in Norway and Japan increased somewhat. The nominal share declines in manufacturing are dominated by a fall in the relative price of manufactures relative to other sectors, however, which in turn has been driven by fundamental productivity and demand patterns in the economy. This is clear from the constant price chart, which shows a fairly steady share for manufactures in the United States, Germany and France and a clear upward trend in Japan. In contrast, the energy boom nations saw sharply lower shares beginning in the early 1980 s that continued unabated until 1985 for the Netherlands, and even latter for Norway and the United Kingdom. Clearly, the manufacturing sectors in the energy-boom nations have not performed as well by this yardstick as our comparison countries since the mid-1970s.

Nonetheless, one should interpret statistics of this nature cautiously. First, descriptive statistics allow insights into broad 
Chart 7

\section{THE ENERGY SECTOR}

AS A PERCENTAGE OF GDP, AT CURRENT PRICES

INDEX: $1975=100$

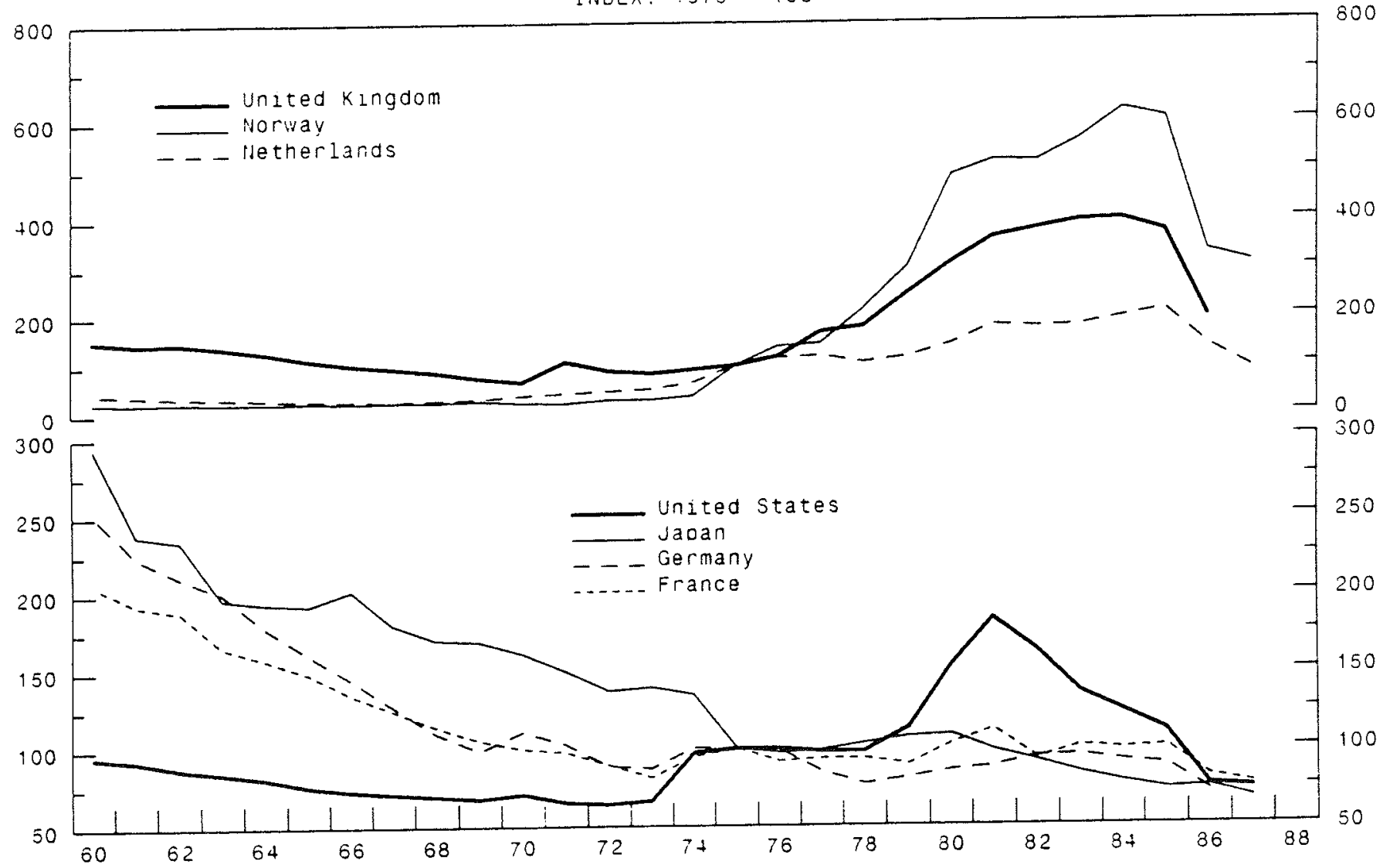

AS A PERCENTAGE OF GDP, AT CONSTANT PRICES

INDEX: $: 975=100$

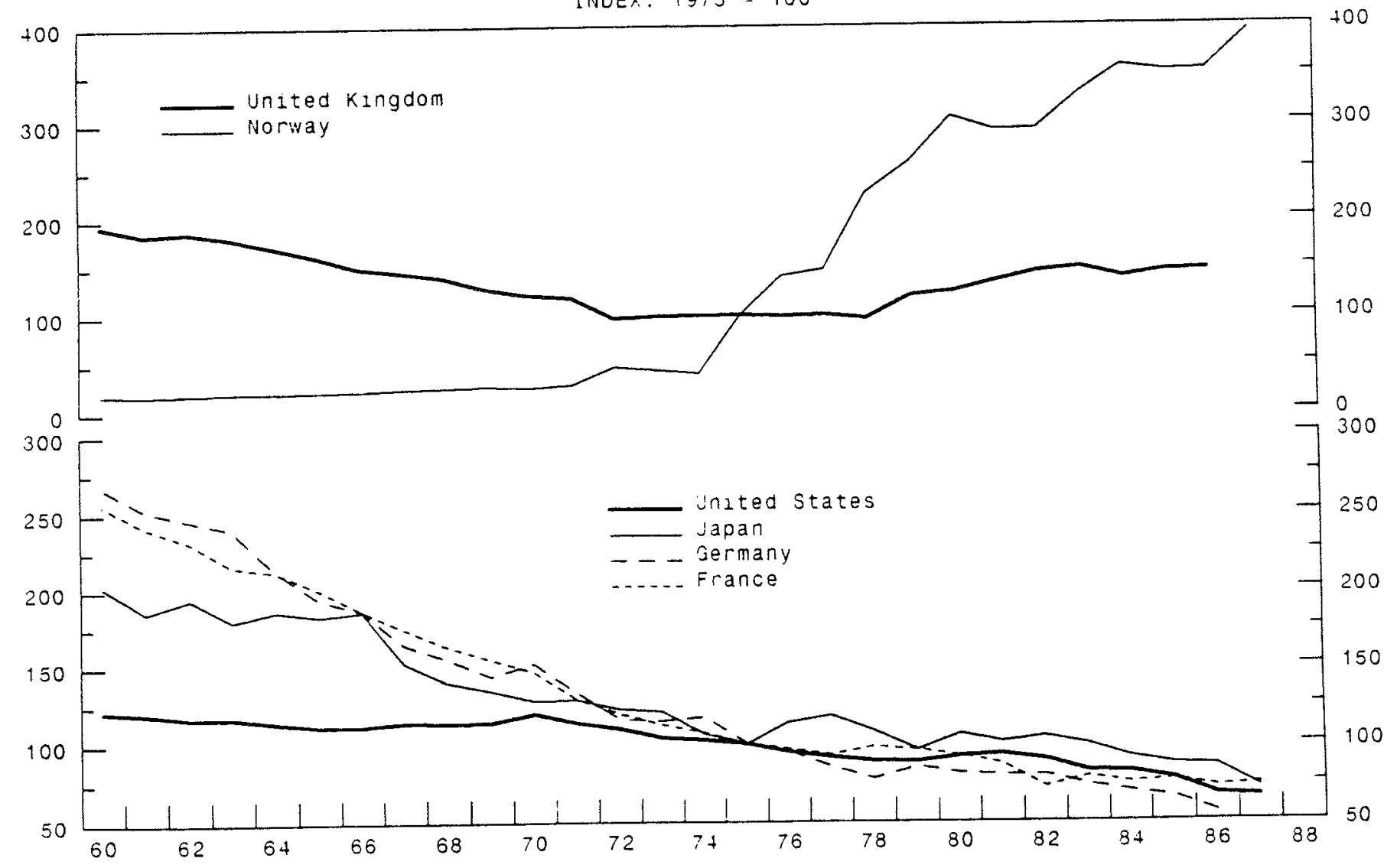


Chart 8

THE MANUFACTURING SECTOR

AS A PERCENTAGE OF GDP, AT CURRENT PRICES

INDEX: $1960=100$

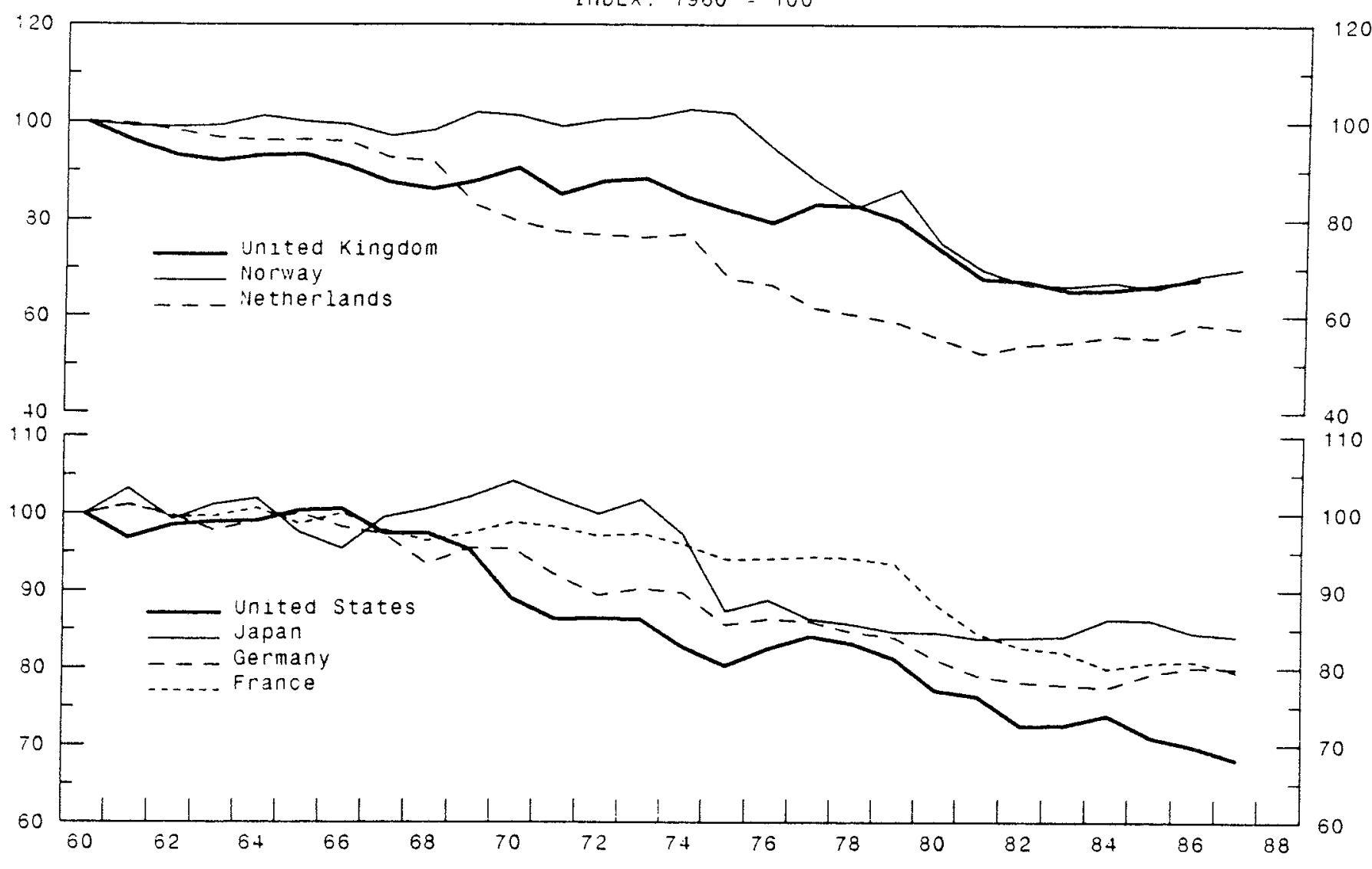

AS A PERCENTAGE OF GDP, AT CONSTANT PRICES INDEX: $1960=100$

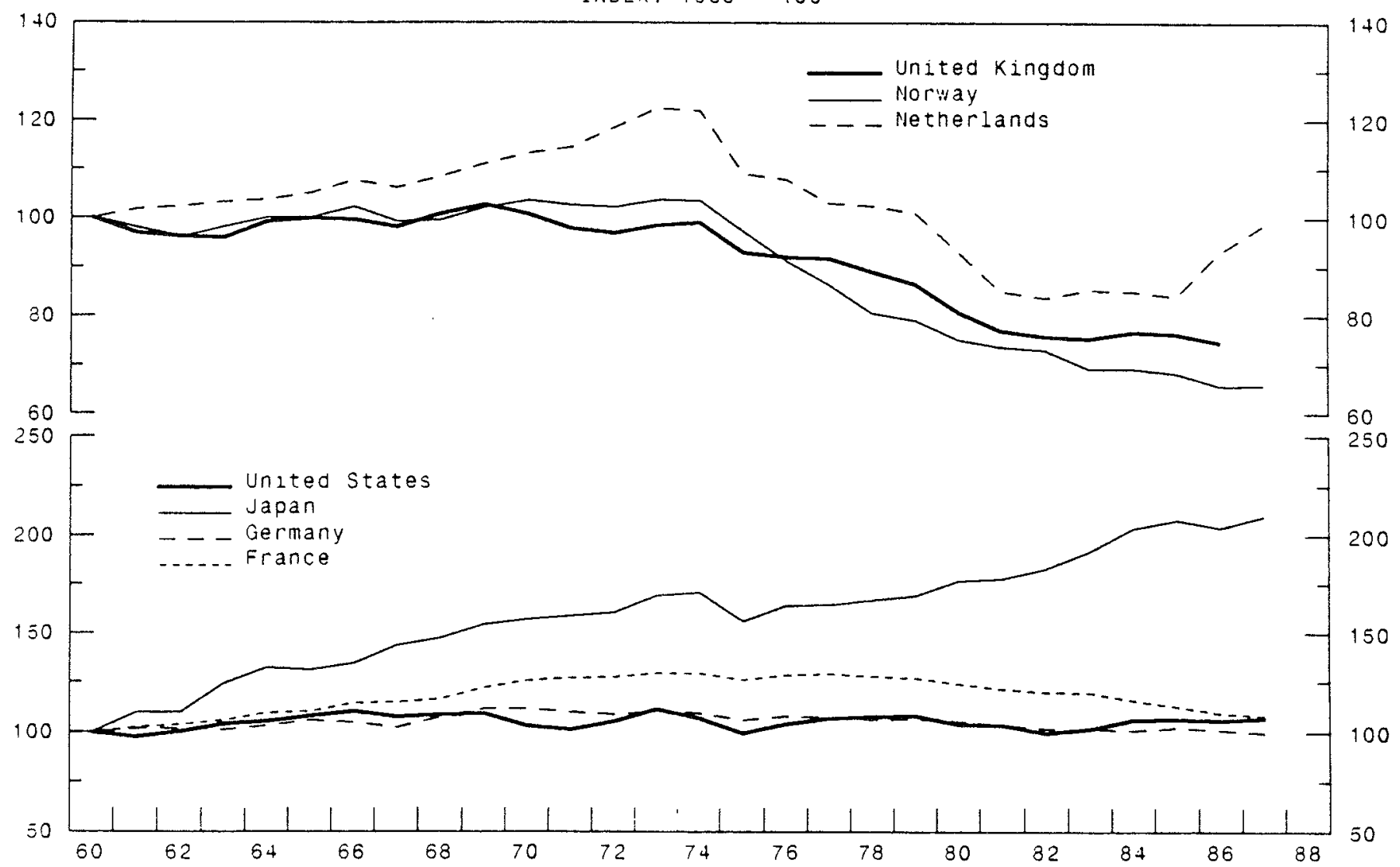


tendencies but do not provide evidence on systematic relationships between manufacturing sector robustness and oil booms. The evidence presented largely is supportive of the view that an oil boom has an immediate adverse effect on manufactures, via a decline in international competitive position and rise in wage costs. It not clear whether this "episodic effect" is sustained, however. Second, although the data are generally consistent with the predictions of the Dutch disease theory, more formal statistical procedures are necessary to test for the systematic influence of oil booms as well as other potential alternative explanations for the weakness of manufactures in these nations during particular episodes.

\section{Empirical methodology}

In our empirical work we investigate the dynamic relationship between the energy sector of the economy and the manufacturing sector. In particular, the fundamental prediction of the Dutch disease energy boom theory is that a boom in this sector will "crowd out" the manufacturing sector. This was derived algebraically in the context of the trade theoretic approach and shown diagrammatically in the context of the open economic macroeconomic approach. Two major alternative explanations for manufacturing sector weakness in a number of countries during the $1970 \mathrm{~s}$ and early $1980 \mathrm{~s}$ also were discussed in this context, i.e. the influence of contractionary monetary policies (especially in the United Ringdom) and world-wide increases in energy prices. It is important to distinguish between these alternative explanatory factors in an attempt to test the Dutch disease hypothesis as it applies to Norway, the Netherlands, and the United Kingdom.

As discussed above, the dynamics of manufacturing sector adjustment to the discovery and exploitation of an energy resource, as well as to energy price and monetary shocks, is quite complicated. The dynamics depend on both underlying structural parameters, the speeds of adjustment in asset and goods markets, as well as the formation of expectations and the general anticipation of policies - factors which will differ from country to country and are difficult to capture empirically in a structural 
econometric model. For this reason, we employ the vector autoregressions (VAR) methodology to decompose the variance of manufacturing output fluctuations at different time horizons into that part attributable to energy booms and disturbances in monetary conditions and world energy prices. This methodology is particularly appropriate in cases such as this where theory does not provide us with a clear guide in modelling potentially complicated dynamic relationships. 20

We examine a multivariate system that includes real energy prices, energy output, money/credit supply and manufacturing output. The objective is to examine the sources of the economic disturbances that have affected manufacturing output in the United Kingdom, the Netherlands and Norway. Residual movements in manufacturing output in these countries not attributable to energy prices, energy output or money/credit supply are interpreted as arising from other factors. In order to decompose the disturbances into their various components we must impose some restrictions on the multivariate dynamic system. Such identifying restrictions have taken a variety of forms in the recent literature. One approach achieves identification by imposing a priori restrictions on the contemporaneous interactions among the variables in the system. These restrictions normally take the form of exclusion restrictions, and in the context of VAR systems include the recursive structure popularised by sims (1980) and the simultaneous equations approach used by Blanchard and Watson (1986), Bernanke (1986) and Walsh (1987).

We employ the recursive structure approach to estimate the sources of fluctuations in manufacturing output. The specific model can be represented by a $k \times 1$ vector of endogenous variables $z_{t}$ (in this case a $4 \times 1$ vector comprising energy prices, energy output, money/credit supply and manufacturing output) with Wold representation given by

$$
z_{t}=B(L) \varepsilon_{t},
$$

20 Both the advantages and limitations of the VAR methodology are well known. See Cooley and LeRoy (1987) for a comprehensive discussion and critique of the VAR approach, as well as a useful comparison with estimation procedures associated with standard structural models. 
where $B(L)=B_{0}+B_{1} L+B_{2} L^{2}+\ldots$ is a kxk matrix of polynomials in the lag operator $L$ and $\varepsilon_{t}$ is a $k x l$ vector of white noise disturbance terms. We assume that $B_{0}$ has $1^{\prime} s$ along its diagonal and that $E \varepsilon \varepsilon,=\Sigma_{\varepsilon}$ is a diagonal matrix. The $\varepsilon$ 's are viewed as the fundamental structural disturbances, and we are interested in estimating the response of the elements of $z$ to innovations in the elements of $\varepsilon$. For example, one element of $\varepsilon$ represents the energy sector, $\pi$, and we are interested in the contribution of this shock to manufacturing output fluctuations. In this framework $\pi$ is interpreted as a disturbance (unpredicted fluctuation) in energy output. Hence, we focus on the supply-side effects of the development of the energy sector in line with the trade-theoretic approach, as opposed to the wealth effects of a resource discovery emphasized in the open economy macro-economic models.

We do not observe $\pi$ or the other fundamental disturbances (elements in vector $\varepsilon$ ) and they must be estimated. One way to summarise the sample information contained in our observations is to estimate the VAR representation of $z_{t}$ :

$$
H(L) z_{t}=u_{t} \text {, where } H(0)=I .21
$$

Inverting the VAR representation yields $z_{t}=D(L) u_{t}$, where $D(L)=H(L)^{-1}$ and $D(0)=I$. In terms of $(14), D(L)=B(L) B(0)^{-1}$ and $u_{t}=B(0) \varepsilon_{t}$. Thus, in order to recover estimates of the structural disturbances, $\varepsilon_{t}$, from the estimated VAR residuals, $u_{t}$, it is necessary to estimate $B(0)$.

The covariance matrix of the VAR residuals, $\Sigma_{u}$, is related to $B(0)$ and $\Sigma_{\varepsilon}$ by

$$
\Sigma_{u}=B(0) \Sigma_{\varepsilon} B(0)
$$

We have $k(k+1) / 2$ bits of sample information in $\Sigma_{u}$ to estimate the $k^{2}$ unknown elements in $B(0)$; in general, $k^{2}-k(k+1) / 2=k(k-1) / 2$ additional restrictions are required for identification. The approach to identification pioneered by sims which we employ assumes that $B(0)$ is lower triangular. This imposes $k(k-1) / 2$ restrictions on the elements of $B(0)$.

21 That is, $H(L)=I+H, L+H_{2} L^{2}+\ldots$ 
Economically, this is equivalent to assuming a recursive structure. Once $B(0)$ is estimated, then estimates of the structural disturbances, $\varepsilon_{t}$, are given by $B(0)^{-1} u_{t}$, where $u_{t}$ is the vector of VAR residuals. The recursive structure imposed on $B(O)$ is ordered: energy price, energy output, money/credit and manufacturing. This ordering allows the three potential explanatory factors to exert the largest possible influence on movements in manufacturing output, and in effect minimises the contemporaneous residual influence on manufactures.

\section{Non-stationarity and Cointegration}

In the way of preliminaries, we begin with several tests of data stationarity and cointegration. Time series analysis in economics often faces the "non-stationarity" problem with data in level form (e.g. upward or downward trends), which invalidates traditional tests of statistical inference. A standard practice in this circumstance is to estimate models with data in first difference form. ${ }^{22}$ This transformation may be sufficient to induce stationarity in the data and thereby allow tests of statistical inference and hypothesis testing to be applied. ${ }^{23}$ One problem with this approach, however, is that any information on longer-run tendencies or co-movement between variables is lost when first difference data are analysed. ${ }^{24}$ For example, the hypothesised negative linkage between energy boom and manufacturing output may be difficult to detect in short-term movements in the data if there are substantial unemployed resources in the economy. To the extent that unemployed resources are a temporary cyclical

22 Phillips (1985) has demonstrated that the distributions of the conventional statistics applied to non-stationary series are not at all like those for stationary series. The coefficients of the regressions do not converge as sample size increases, and the distributions of the t-test diverge so that there are no asymptotically correct critical values for conventional significance tests. See Hendry (1986) for a review of this problem.

23 Granger and Newbold (1984) point out that the spurious regression problem is widespread in the econometrics literature. Nelson and Plossner (1982) argue strongly that using first-differencing data in regressions is far superior to using data in levels when common trends are a potential problem.

24 See Hendry and Mizon (1978) for the argument for retaining such variables in level form in well-specified regressions. 
phenomenon, however, a "crowding out" pattern consistent with the Dutch disease hypothesis nonetheless may be identifiable in longer-term data movements. In this case, long-run information is important and should be imbedded in the specification of the model. This long-run relationship is tested by standard cointegration tests ${ }^{25}$, and if found to be significant may easily be incorporated into the VAR as a restriction on the dynamic adjustment process. This is a generalised form of an error correction model. 26

In general terms, two variables are said to be cointegrated when each variable taken separately is non-stationary (time varying mean and variance) yet a linear combination of the two is stationary. ${ }^{27}$ We are interested in the potential long-term relationship between real output in the manufacturing sector $\left(y_{m t}\right)$ and the oil boom variable $\left(\pi_{t}\right)$ :

$$
y_{m t}=\tau+\alpha \pi_{t}+\mu_{t}
$$

where $\alpha$ and $\tau$ may be interpreted, for example, as the reduced form coefficients ( $\alpha$ is hypothesised to be negative) representing complex composites of the structural coefficients of the trade-theoretic structural model, shown in equation 8 . Assume that both $y_{m t}$ and $\pi_{t}$ are non-stationary and need to be differenced once to induce stationarity. In general, most

25 The literature on cointegration was pioneered by Granger and Weiss (1983), Granger (1983), Granger and Engle (1987), and others .

26 See Campbell and Shiller (1988).

27 Engle and Granger (1987) define cointegration more generally: a set of variables is cointegrated of order $(d, b)$ if each variable individually is integrated of order $d$, but at least one linear combination exists which is of order (d-b), where (d-b) is greater than zero. Although most studies focus on bivariate relationships, the general principle extends to a multivariate setting. Moreover, the linear combination is typically taken to be a difference series, but it may also be additive. For example, given full employment of resources, a rise in the output of one sector may limit growth of, or decrease, output in other sectors of the economy. The addivitive linear combination of sectoral output levels (or growth rates) may be cointegrated in an equilibrium (full employment) setting. 
linear combinations of $\mathrm{y}_{\mathrm{mt}}$ and $\pi_{t}$ will also be non-stationary. ${ }^{28}$ However, there may exist a linear combination of $y_{m t}$ and $\pi_{t}$ that is stationary. For example, there may be a number $\alpha$ such that $y_{m t}-\alpha \pi_{t}=\mu_{t}$ is stationary (assume $\tau=0$ for expositional purposes). In this special case, $y_{m t}$ and $\pi_{t}$ are said to be cointegrated of order $(1,1)$ with a cointegration coefficient of $\alpha{ }^{29}$ Thus, if $y_{m t}$ and $\pi_{t}$ are cointegrated with a factor of $\alpha$, then they cannot drift too far apart because their linear combination, $y_{m t}-\alpha \pi_{t}$, is stationary. In this case, the stationary linear combination should be imbedded as a restriction in the general VAR in order to allow an "error correction" adjustment. However, if they are not cointegrated, there is no pressure for the two series to converge and their linear combination $\left(\mu_{t}\right)$ will be non-stationary - that is, it may take on arbitrarily large values over time.

Granger and Engle (1987) suggest several tests for examining the hypothesis that two time series are cointegrated. Following determination of the order of integration for the individual time series, all of these tests involve regressing $y_{m t}$ on $\pi_{t}$, where $\tau$ is the estimated constant term, $\alpha$ the estimated cointegration coefficient, and $\mu_{t}$ the estimated residual. The first tests proposed by Granger and Engle involve the Durbin-Watson statistic (DW) from the regression. If the $D W$ statistic is sufficiently large (significantly above zero; a non-stationary series will have a DW statistic approaching zero), the two series are cointegrated because the residual from their difference is stationary. Similarly, Dickey-Fuller type regressions (Dickey and Fuller, 1979 and 1981) may be employed to test whether the estimated residual series $\left(\mu_{t}\right)$ has a unit root. ${ }^{30}$ If there is a

28 However, a linear combination of the two differenced series will be stationary (since we assumed that each series individually was stationary after first differencing).

29 The first term of the order of integration refers to the number of times it is necessary to difference the individual time series to attain stationarity; the second term is the reduction in the number of times it is necessary to difference $\mu$ to achieve stationarity.

30 If the $\mu_{t}$ time series has a unit root it follows the process:

$$
\mu_{t}=\mu_{t-1}+e_{t}
$$

where $e_{t}$ is white noise. In this circumstance, any shock to $\mu_{t}$ (realisation of $e_{t}$ ) will permanently affect the level of the variable

(Footnote Continued) 
unit root, $\mu_{t}$ can take on arbitrary large values (it is non-stationary), which means that there is no long-run constraint on the movements of $y_{m t}$ and $\pi_{t}$, i.e. they are not cointegrated.

Specifically, the Dickey-Fuller (DF) test is based on the regression:

$$
\left(\mu_{t}-\mu_{t-1}\right)=p \mu_{t-1}+e_{t}
$$

and examines the significance of the $p$ coefficient. If $p$ equals zero, $\mu_{t}$ is non-stationary and cointegration between $y_{m t}$ and $\pi_{t}$ is rejected. If $p$ is significantly negative in value, a unit root in $\mu_{t}$ is rejected and the cointegration hypothesis is accepted. In order to control for the possibility of higher order dynamics in the Dickey-Fuller regression (which assumes a first order model is correct), an augmented version (augmented $D F$, or ADF) is estimated which allows for more lags ( $k$ lags) but still tests for a unit root:

$$
\left(\mu_{t}-\mu_{t-1}\right)=p \mu_{t-1}+\sum_{j-1}^{k} b_{j}\left(\mu_{t-j}-\mu_{t-j-1}\right)+e_{t}
$$

If the true model is a first order case, then the augmented Dickey-Fuller regression is over-parameterised and has lower power than the standard test. However, it is the correct test for higher order cases. 31

(Footnote Continued)

with no tendency towards some constant mean. Both the mean and variance of this series is time-varying, and the latter has a limit value of infinity. Generally, $u_{t}=b \mu_{t-1}+e_{t}$ with $e_{t}$ equal to white noise, or $\mu_{t}-\mu_{t-1}=p \mu_{t-1}+e_{t}^{t}$, where $p=t-1$. If:

(i) $p=0$, then $b=1$ and $\mu_{t}$ has a unit root;

(ii) $\mathrm{p}>0$, then $\mathrm{b}>1$ and $\mu_{t}$ is explosive;

(iii) $p<0$, then $b<1$ and $\mu_{t}^{t}$ is stationary.

31 Granger and Engle (1987) estimate critical values for the DW, DF and augmented DF statistics by simulation methods. Their estimates suggest that the augmented DF test has essentially the same critical values as the DF test and is recommended in most cases. 


\section{Empirical Results}

Quarterly data is used, and the variables are measured in natural logarithms. The data consists of manufacturing output indices, actual physical output measures for oil and natural gas, real dollar price of crude oil, and either broad money aggregates (United Kingdom and the Netherlands) or total bank credit (Norway). The sample time periods are 67:2-89:2 for the Netherlands, 71:3-89:1 for Norway, and 76:1-89:2 for the United Kingdom. These samples were determined by the availability of data on oil and natural gas production. Complete definitions and sources of the data are provided in the data appendix.

\section{Preliminaries}

Table 2, pane1 A, reports the Dickey-Fuller (DF) and adjusted Dickey-Fuller (ADF) unit root tests on both levels and first differences of $y_{m t}$ and $\pi_{t}$. The null hypothesis is that there exists a unit root, and failure to reject the null indicates that the variable is non-stationary. These results show that the $\mathrm{DF}$ and $\mathrm{ADF}$ tests are consistent in not being able to reject a unit root (rejecting stationarity) for all of the variables in level form except manufacturing output in the Netherlands. The unit root hypothesis is easily rejected for first difference series using the DF test, however, and by the ADF test as well in all cases where this test is appropriate, i.e. where there is indication of residual autocorrelation present in the time series. That is, only in the case of the first difference of UK manufacturing output does the ADF test indicate non-stationarity, but in this case there is no evidence of residual autocorrelation. Five of the six variables therefore appear integrated of order one, i.e. non-stationary in levels and stationary in changes.

The estimates of the coefficient of cointegration $(\alpha)$ are presented in panel B for the United Kingdom and Norway - the two cases where the stationarity tests indicate that both petroleum output and manufacturing output are integrated of order one. These cointegrating 
Table 2

Testing for long-run equilibrium relationships between the energy and manufacturing sectors

A. Preliminary stationarity tests

\begin{tabular}{|c|c|c|c|c|}
\hline \multirow[b]{3}{*}{$\begin{array}{l}\text { Norway } \\
\quad \text { Petroleum output } \\
\quad \text { Manufacturing output }\end{array}$} & \multicolumn{2}{|c|}{ Dickey-Fuller } & \multicolumn{2}{|c|}{ Augmented Dickey-Fuller ${ }^{1}$} \\
\hline & Log levels & $\begin{array}{c}\text { First } \\
\text { differences }\end{array}$ & Log levels & $\begin{array}{c}\text { First } \\
\text { differences }\end{array}$ \\
\hline & $\begin{array}{r}1.74 \\
-\quad 1.96\end{array}$ & $\begin{array}{r}6.50^{*} \\
-11.49^{*}\end{array}$ & $\begin{array}{r}1.24 \\
-\quad 1.66\end{array}$ & $\begin{array}{l}-2.802 * \\
-\quad 3.622^{2 *}\end{array}$ \\
\hline $\begin{array}{l}\text { Netherlands } \\
\quad \text { Vatural gas output } \\
\text { Manufacturing output }\end{array}$ & $\begin{array}{l}0.57 \\
4.70^{*}\end{array}$ & $\begin{array}{l}-9.31^{*} \\
-\quad 7.56^{*}\end{array}$ & $\begin{array}{l}0.86 \\
3.51^{*}\end{array}$ & $\begin{array}{l}3.62^{*} \\
-\quad 3.48^{*}\end{array}$ \\
\hline $\begin{array}{l}\text { United Kingdom } \\
\text { Petroleum output } \\
\text { Wanufaccuring output }\end{array}$ & $\begin{array}{l}1.67 \\
0.69\end{array}$ & $\begin{array}{l}-4.49^{*} \\
-5.26^{*}\end{array}$ & $\begin{array}{l}0.16 \\
0.36\end{array}$ & $\begin{array}{l}3.73^{*} \\
-\quad 2.46^{2}\end{array}$ \\
\hline
\end{tabular}

B. Cointegrating vector ${ }^{3}$

$I-\hat{a} P=\dot{U}$

\begin{tabular}{|c|c|c|c|c|c|}
\hline & $\hat{a}$ & t-statistic & DW & $\overline{\mathrm{R}}^{2}$ & SEE \\
\hline Norway & 0.02 & 4.91 & 0.33 & 0.25 & 0.04 \\
\hline United Kingdom & -0.02 & -1.20 & 0.07 & 0.01 & 0.07 \\
\hline
\end{tabular}

C. Stationarity of $\hat{u}$

\begin{tabular}{|l|c|c|}
\hline & Dicky-Fuller & Augmented Dicky-Fuller \\
\cline { 2 - 3 } Norway $\ldots \ldots \ldots \ldots \ldots \ldots$ & 2.15 & 1.70 \\
Lnited Kingdom $\ldots \ldots \ldots$ & 0.18 & -0.78 \\
\hline
\end{tabular}

* Denotes a significance level of $95^{\circ} \circ$ or greater.

Augmented D-F test incorporates four lags of the differenced series.

2 Volag in augmented D-F test is significant at $90^{\circ} \%$ ievel.

3 Log level of manufacturing output, I, regressed on a constant plus the log level of petroleum output, $P$; $\hat{a}$ is the slope coefficient (the coefficient of cointegration) and $\hat{v}$ is the residual series. 
regressions are relatively weak in several respects ${ }^{32}$. The total explained variance of the equation is quite low for variables in level form, making interpretation of a close long-run relationship between the two variables difficult. Moreover, the unit root tests of the "equilibrium error" (residuals from the cointegration regression) cannot reject non-stationarity, i.e. we cannot reject the hypothesis that there is no long-term tendency for manufactures output to be adversely affected by the size of the oil/natural gas sector (panel $\mathrm{C}$ ). These results indicate that there is no cointegration between the two variables, and that specification in first difference form within an unrestricted VAR model is appropriate.

\section{Variance Decompositions}

The manufacturing output variance decompositions derived from estimating the VAR model (equation 14) are presented in Tables 3 to 6 . The first VAR estimated, with variance decompositions reported in Table 3 , is a bivariate model with oil/natural gas output and manufacturing output. Results from estimation of the complete model are presented in Table 4, and several extensions of the framework are considered in Tables 5 and 6 .

The bivariate VAR model results in Table 3 for lag lengths of both four and six quarters indicate that only a relatively small percentage of the variance in manufacturing growth is attributable to oil and natural gas output innovations. Considering the medium-term forecast error variance estimates ( 20 quarters), only between 8 to 13 percent is attributable to oil/natural gas production disturbances in the Norway, 5 to 8 percent in the Netherlands, and 3 to 12 percent in the United Kingdom. ${ }^{33}$ The systematic relationship between the two series is not strong for any of the countries over the full sample period. During particular episodes rapid development of oil and gas resources may have played a significant role in "crowding out" the manufacturing sector through direct resource movement effects and indirect effects working through an increase in aggregate

32 See Hendry (1986) for a discussion of the interpretation and evaluation of cointegrating regression results.

33 This result is consistent with Bank of England study (1982) which makes the argument that the strength of sterling was largely due to factors other than North Sea oil, and that no contraction of the industrial sector need be associated with the development of the oil sector. 
Table 3

Manufacturing growth fluctuations variance decompositions

Two-variable system

\begin{tabular}{|c|c|c|c|c|}
\hline \multirow[b]{2}{*}{$\begin{array}{l}\text { Quarters } \\
\text { ahead }\end{array}$} & \multicolumn{2}{|c|}{ Four lags } & \multicolumn{2}{|c|}{ Six lags } \\
\hline & $\begin{array}{l}\text { Petroleum/ } \\
\text { natural gas }\end{array}$ & Other factors & $\begin{array}{l}\text { Petroleum/ } \\
\text { natural gas }\end{array}$ & Other factors \\
\hline \multicolumn{5}{|c|}{ Norway } \\
\hline 1 & 0 & 100 & 0 & 100 \\
\hline 5 & 8 & 92 & 9 & 91 \\
\hline 10 & 8 & 92 & 13 & 87 \\
\hline 15 & 8 & 92 & 13 & 87 \\
\hline 20 & 8 & 92 & 13 & 87 \\
\hline \multicolumn{5}{|c|}{ Netherlands } \\
\hline 1 & 0 & 100 & 0 & 100 \\
\hline 5 & 7 & 93 & 5 & 95 \\
\hline 10 & 8 & 92 & 5 & 95 \\
\hline 15 & 8 & 92 & 5 & 95 \\
\hline 20 & 8 & 92 & 5 & 95 \\
\hline \multicolumn{5}{|c|}{ United Kingdom } \\
\hline 1 & 1 & 99 & 0 & 100 \\
\hline 5 & 3 & 97 & 8 & 92 \\
\hline 10 & 3 & 97 & 12 & 88 \\
\hline 15 & 3 & 97 & 12 & 88 \\
\hline 20 & 3 & 97 & 12 & 88 \\
\hline
\end{tabular}

Votes: Variables entered as $\log$ first differences. Variance decompositions report the percentage of the $n$ quarter ahead manufacturing forecast error variance which is attributable to either the development of the petroleuminatural gas sector or other factors. VAR model estimated is an unconstrained system. 
demand. But these effects have seemingly been more episodic, and perhaps concentrated in the early stages of oil/gas development, rather than predictable and systematic.

The results from the complete model, reported in Table 4, are consistent with the finding that oil/natural gas output innovations have not played a major systematic role in generating manufacturing output fluctuations. The highest percentage of manufacturing forecast error variance explained by oil/gas shocks is 10 percent for Norway, and is estimated at only 6 and 7 percent for the United Kingdom and the Netherlands, respectively. The estimated impact of oil/natural gas on Norway seems small given the large revenues to the economy associated with development of this sector, however. ${ }^{34}$ Nonetheless, this finding is consistent with the conclusion of Cappelen, et al. (1985), however, who attribute it to (i) the extensive subsidy program towards exposed (tradable goods industries exposed to international competition) industries, and (ii) increase in the labour supply associated with higher female participation rates. ${ }^{35}$ Moreover, manufacturing industry has been bolstered to the extent that the national oil company has favoured domestic supplier industries (e.g. oil platforms, piping, etc.) over foreign suppliers. That the contractionary effect would have been larger in the absence of these three factors is implicit in the simulation exercise results of $B$ jerkholt et al. $(1981)^{36}$.

34 The results reported for Norway are for raw oil production. A composite raw oil production and natural gas production proxy was also employed in the VAR analysis. Somewhat surprisingly, these results attributed less of the variance in manufacturing to the composite variable than to raw oil production alone.

35 Investigating the Norwegian experience, Cappelen, et al. (1985) state: "Although some changes in the disfavour of exposed industries have taken place, they are nowhere near the magnitude sometimes prophesied by the Dutch Disease literature...sectoral redistribution of the labour force as predicted by the Dutch Disease literature was dampened mainly as a consequence of the increased labour supply and increased subsidies to exposed industries." ( $p$. 38) Cappelen, et. al. do not study the structural changes between sheltered and exposed sectors, however. Instead, their aggregation is between the oil sector and the rest of the economy in aggregate.

36 The Bjerkholt et al. (1981) study does not represent a statistical analysis of the actual effects of the oil boom, however. Rather, it 
Table 4

Manufacturing growth fluctuations variance decompositions

\begin{tabular}{|c|c|c|c|c|}
\hline $\begin{array}{l}\text { Quarters } \\
\text { ahead }\end{array}$ & $\begin{array}{l}\text { Real energy } \\
\text { price }\end{array}$ & $\begin{array}{l}\text { Petroleum/ } \\
\text { natural gas }\end{array}$ & $\begin{array}{l}\text { Money/ } \\
\text { credit }\end{array}$ & $\begin{array}{l}\text { Other } \\
\text { factors }\end{array}$ \\
\hline \multicolumn{5}{|c|}{ Norway } \\
\hline 1 & 1 & 1 & 2 & 96 \\
\hline 5 & 3 & 10 & 4 & 82 \\
\hline 10 & 5 & 10 & 5 & 80 \\
\hline 15 & 6 & 10 & 5 & 79 \\
\hline 20 & 6 & 10 & 5 & 79 \\
\hline \multicolumn{5}{|c|}{ Netherlands } \\
\hline 1 & 1 & 0 & 1 & 98 \\
\hline 5 & 8 & 7 & 4 & 81 \\
\hline 10 & 9 & 7 & 4 & 80 \\
\hline 15 & 9 & 7 & 4 & 80 \\
\hline 20 & 9 & 7 & 4 & 80 \\
\hline \multicolumn{5}{|c|}{ United Kingdom } \\
\hline 1 & 11 & 1 & 9 & 82 \\
\hline 5 & 19 & 4 & 12 & 66 \\
\hline 10 & 23 & 5 & 12 & 60 \\
\hline 15 & 23 & 6 & 13 & 59 \\
\hline 20 & 23 & 6 & 13 & 59 \\
\hline
\end{tabular}

Notes: Variance decompositions report the percentage of the $n$ quarter ahead manufacturing forecast error variance which is attributable to the variable listed in the column. The moving average representation of the time series is derived from a 4-variable, 4-lag, unconstrained VAR system ordered as (energy price - petroleum output - money - manufacturing output). All variables entered as first differenced log levels. 
World oil price shocks, in contrast, are estimated to have caused a large percentage of manufacturing output variance in the United Kingdom (23 percent at a 10 to 20 quarter horizon). This is consistent with the results of Bean (1987) and Bruno and Sachs (1982). However, world energy price shocks seemed to play a smaller role in Norway and the Netherlands. ${ }^{37}$ Similarly, only in the United Kingdom are monetary factors identified as having played a significant role in unanticipated manufacturing output fluctuations. This is consistent with the findings of Niehans (1981) and Buiter and Miller (1982) for the United Kingdom. Moreover, the relatively small role for monetary policy in this context for the Netherlands also is suggested by Kremers (1986), which he attributes to the size and openness of the economy. This characterisation, of course, also applies to Norway. However, the explanatory factors identified by the models leave a significant component of manufacturing output variance unexplained. Even in the case of the United Kingdom, where several important explanatory factors were identified, the unexplained variance in manufacturing is fairly steady at about 60 percent of the total after a period of 10 quarters.

The model estimates reported in Table 4 do not include a measure of international competitiveness as an explanatory variable. Although important as a channel through which Dutch Disease effects are transmitted to the economy, neither real exchange rates nor relative unit labour costs (in international comparison) represent independent sources of manufacturing decline in the two models developed in section $I$. These are endogenous variables in the two models posited and represent channels of transmission through which oil/natural gas booms influence manufacturing

(Footnote Continued)

is a simulation exercise within the context of an input-output growth model designed to evaluate the likely effects on a number of sectors in the economy associated with various scenarios for oil sector development, productivity changes, and so on.

37 Kremers (1986) notes that the role of natural gas as a partly non-traded intermediate input in manufacturing is very important in the Netherlands. He suggests that this has tended to reinforce the contractionary impact of the oil price rise on the tradables sector, since that sector had become more energy intensive with the development of the natural gas resources. (p. 102) We find only weak evidence of a systematic linkage between oil prices and manufacturing output, however. 
output, but are not fundamental exogenous determinants of the allocation of resources between sectors. ${ }^{38}$ Table 5 reports estimates of a 2 variable VAR system that attempts to quantify the extent to which oil/gas fluctuations have influenced international competitiveness, and thereby played a role as a channel of transmission through which energy booms have influenced the manufacturing sector. International competitiveness is measured by the trade weighted exchange rate deflated by relative unit labour costs, i.e. a common proxy for the real exchange rate.

These results do not indicate a strong systematic relationship between growth in the oil/gas sector and fluctuations in international competitiveness, however. Only in the case of Norway do oil/gas shocks seem to account for more than 10 percent of the variance in real exchange rates (10 percent after a period of 10 quarters). The negligible effect found for the United Kingdom supports the argument made by Niehans (1981) and the Bank of England (1982) that sterling appreciation in the late 1970s largely was attributable to factors other than North Sea oil. Similarly, the event study findings of Sheffrin and Russell (1984) provide no evidence that sterling appreciation is associated with new information on the size of North Sea oil reserves for the United Kingdom. Nonetheless, in light of the well known difficulties in attempting to systematically explain real exchange rate movements (Meese and Rogoff, 1985), a cautious interpretation of the results is appropriate.

Finally, for completeness we report in Table 6 an extended VAR model which includes the real exchange rate as an explanatory variable in manufacturing output movements. Real exchange rates do not seem to play a significant causal role in explaining manufacturing output movements. The possible exception is the United Kingdom where approximately 10 percent of the forecast error variance is attributable to real exchange rate shocks. on the other hand, the relative variance explained by the other variables in the system - real energy prices, oil/natural gas output, and money/credit - is very similar to the estimates reported in Table 4. 0il sector developments in the medium-term have seemingly played the most role in Norway, and the least important role in the United Kingdom. In contrast, world energy price shocks and money shocks have played important roles in

38 However, other models may provide real exchange rates or unit labour cost fluctuations with an exogenous element. 
Table $\mathbf{5}$

\section{Real exchange rate fluctuations} variance decompositions

Two-variable system

\begin{tabular}{|c|c|c|}
\hline $\begin{array}{l}\text { Quarters } \\
\text { ahead }\end{array}$ & $\begin{array}{l}\text { Petroleum/ } \\
\text { natural gas }\end{array}$ & $\begin{array}{l}\text { Other } \\
\text { factors }\end{array}$ \\
\hline \multicolumn{3}{|c|}{ Norway } \\
\hline 1 & 0 & 100 \\
\hline 5 & 11 & 89 \\
\hline 10 & 13 & 87 \\
\hline 15 & 13 & 87 \\
\hline 20 & 13 & 87 \\
\hline \multicolumn{3}{|c|}{ Netherlands } \\
\hline 1 & 1 & 99 \\
\hline 5 & 1 & 99 \\
\hline 10 & 1 & 99 \\
\hline 15 & 2 & 98 \\
\hline 20 & 2 & 98 \\
\hline \multicolumn{3}{|c|}{ United Kingdom } \\
\hline 1 & 1 & 99 \\
\hline 5 & 2 & 98 \\
\hline 10 & 2 & 98 \\
\hline 15 & 2 & 98 \\
\hline 20 & 2 & 98 \\
\hline
\end{tabular}

Lotes: See notes to Tables 3 and 4 . The unconstrained VAR system is ordered petroleummanufacturing. 
Table 6

Manufacturing growth fluctuations variance decompositions

Five-variable system

\begin{tabular}{|c|c|c|c|c|c|}
\hline $\begin{array}{l}\text { Quarters } \\
\text { ahead }\end{array}$ & $\begin{array}{l}\text { Real energy } \\
\text { price }\end{array}$ & $\begin{array}{l}\text { Petroleum/ } \\
\text { natural gas }\end{array}$ & $\begin{array}{l}\text { Real } \\
\text { exchange } \\
\text { rate }\end{array}$ & $\begin{array}{l}\text { Money/ } \\
\text { credit }\end{array}$ & $\begin{array}{l}\text { Other } \\
\text { factors }\end{array}$ \\
\hline \multicolumn{6}{|c|}{ Norway } \\
\hline 1 & 1 & 3 & 0 & 5 & 91 \\
\hline 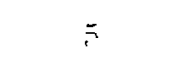 & 3 & 12 & 6 & 7 & 73 \\
\hline 10 & 6 & 12 & 6 & 7 & 69 \\
\hline 15 & 6 & 12 & 6 & 8 & 68 \\
\hline 20 & 6 & 12 & 6 & 8 & 68 \\
\hline \multicolumn{6}{|c|}{ Netherlands } \\
\hline 1 & 2 & 0 & 0 & 1 & 96 \\
\hline 5 & 8 & 7 & 2 & 4 & 80 \\
\hline 10 & 9 & 7 & 2 & 4 & 77 \\
\hline 15 & 9 & 8 & 2 & 4 & 77 \\
\hline 20 & 9 & 8 & 2 & 4 & 77 \\
\hline \multicolumn{6}{|c|}{ United Kingdom } \\
\hline 1 & 17 & 0 & 3 & 7 & 73 \\
\hline 5 & 22 & 4 & 8 & 11 & 55 \\
\hline 10 & 26 & 6 & 9 & 11 & 48 \\
\hline 15 & 26 & 6 & 9 & 12 & 48 \\
\hline 20 & 26 & 6 & 9 & 12 & 48 \\
\hline
\end{tabular}

Notes: See notes to Tables 3 and 4 . The unconstrained VAR system is ordered as: real energy price - pe:roleum - real exchange rate - money - manufacturing output. Rows may not add to $100 \%$ due to rounding. 
the United Kingdom but have influenced manufacturing developments to a much smaller extent in Norway and the Netherlands.

\section{Summary and Conclusions}

This paper reviews the experiences of Norway, the Netherlands and the United Kingdom with oil and natural gas booms. The focus is on how the development of the oil/natural gas sectors in these economies has influenced the manufacturing sector. The basic maintained hypothesis investigated is that of the "Dutch disease" - the prediction that an energy boom will cause a contraction of the manufacturing sector both through resource movement effects and spending effects.

The summary statistics reviewing the experiences of these nations is partly supportive of the predictions of the "crowding out" hypothesis. Sharp increases in the percentage of total value added contributed by the natural resource sector - both in real and nominal terms - has grown significantly in Norway, the Netherlands and the United Kingdom since the mid-1970s, while at the same time the percentage devoted to manufacturing has declined. Moreover, this statistical profile is particularly evident in comparison to countries not experiencing oil or natural gas booms. The evidence also suggests that these nations experienced trade balance improvements after large scale oil/natural gas production got underway, and sharp deterioration in international competitive positions immediately following the discovery of the energy resource, (measured by a unit labour cost weighted measure of the real exchange rate). At least in the initial stages of natural resource development in these economies, manufacturing 
sector weakness is clearly apparent. ${ }^{39}$ This may be termed evidence in support of "episodic" and transitory negative transmission effects of an oil/natural gas boom to the manufacturing sector.

However, the formal statistical analysis provides only weak support for the view that manufacturing decline is systematically and predictably related to energy booms. Most support for a fairly long-lasting and systematic negative relationship is found in Norway. This is not surprising given the magnitude of the wealth and income flows associated with the Norwegian petroleum sector relative to the size of the rest of the economy, and the Norwegian commitment to full employment policies. Moreover, it is noteworthy that these effects are found despite explicit Norwegian government support and subsidy of traditional industries. In the absence of these programs, much larger net contractionary effects may have been evident. For the United Kingdom, in contrast, we find that factors such as world-wide fluctuations in energy prices and monetary conditions have played more important roles than North Sea oil in systematically and predictably influencing the evolution of manufacturing production. For the economy of the Netherlands, where the term "Dutch disease" was originally applied, very little systematic and long-term net adverse consequences of natural gas development on the manufacturing sector were found.

On balance, these results indicate that the basic prediction of an adverse effect on the manufacturing sector immediately following discovery and exploitation of a natural resource is consistent with the stylised facts of the Norwegian, Dutch, and British experiences. The effects identified are typically at the initial stages of natural resource development, tend to episodic and transitory, and vary widely in each particular case. However, there is little statistical evidence to support the view that an oil boom will have long-lasting effects which leads to

39 As Niehans (1981) points out, however, the oil boom may be transmitted to the economy through both an upward shift in the demand for money (associated with the spending effects of the oil resources) and a rise in aggregate goods demand (associated with wealth effects of the oil discovery) which is causing real exchange rate appreciation and manufacturing sector weakness. He argues that the money demand channel of transmission is likely to be dominant. The empirical work in this paper does not attempt to distinguish between these two channels of transmission, and concentrates instead on the net effect of the oil boom in relation to other potential explanatory factors. 
systematic adverse consequences for the manufacturing sector. Although some sectors are clearly made worse off by development of the natural resource and associated rise in national wealth, other manufacturing industries are benefited. 40 The view that national "deindustrialisation" is the inevitable outcome is not provided much support.

40 Moreover, this basic finding is consistent with the few econometric studies directly investigating the "crowding out" prediction of the theory, although different data sets and empirical methodologies are analysed. Schmidt (1989), for example, conducts an econometric analysis investigating the performance of natural resource-dependent regions in the United States relative to less resource-dependent regions. Schmidt concludes that the Dutch disease did not afflict regional economies (p. 16). Moreover, he finds that natural resource price increases benefited non-resource sectors. Similarly, Bean (1987) finds that the North Sea oil boom has had a net positive effect on the manufacturing sector in the United Kingdom. 


\section{Data Appendix}

\section{Data sources:}

(1) OECD, Main Economic Indicators data tape (OECD)

(2) Central Statistical office (United Kingdom), Monthly Digest of Statistics (CSO), Table 7.1 "Output of the Production Industries", accessed from DRI data tape

(3) Petroleum Intelligence weekly (PIW)

(4) OECD, National Accounts, Detailed Tables, Vol. II (NA)

\section{Variables:}

Norway

Industrial production - manufacturing; seasonally adjusted, index 1985=100; source: OECD

Crude petroleum; thousand tons, monthly averages; source: OECD Credit to the economy (commercial and savings banks); million kroner, end of period; source: OECD

\section{Netherlands}

Industrial production - manufacturing; seasonally adjusted, index $1985=100$; source : OECD

Natural gas; million cubic metres (at $0^{\circ}$ and 1013 millibars); source: $O E C D$

MI plus quasi-money; million guilders, end of period; source: OECD

\section{United Kingdom}

Total manufacturing industries (class: DIV 2-4), seasonally adjusted, (weights $=691$ ), average $1985=100$; source: CSO

Extraction of mineral oil and natural gas (class 13, weights 180); seasonally adjusted, average 1985=100; source: CSO

M1 plus quasi-money; seasonally adjusted, million pounds, end of period; source: $O E C D$ 


\section{Other variables}

US implicit price level (GNP); seasonally adjusted, index 1985=100; source: $O E C D$

Oil price; USD per barrel (n.s.a., monthly averages), Saudi Arabian Light - 34, "F.O.B. netback value" (equivalent crude oil value at the landing port), Rotterdam; prior to July 1973, linked with posted prices; source: $P I W$

Real oil price equals oil price deflated by Us implicit price level.

\section{Charts}

Data derived from NA Source, Table 12, "Gross Domestic Product by Kind of Activity", unless noted otherwise. The "energy sector" comprises line 5 (mining and quarrying); "Manufacturing" comprises 1 ine 10 (manufacturing); "Services" comprises lines 24 (wholesale and retail trade, restaurants and hotels), 32 (finance, insurance, real estate, and business services), 29 (transport, storage and communication), and 38 (community, social and personal services); and "other" is all the remaining value added in GDP. Note that "producers of government services" (line 47) is included in the "other" category. The value added in constant units of national currency (at 1985 prices) was used for every country excepting for the service sector in the United Kingdom. For the volume of services in the United Kingdom, the average of volume indices (1980=100) of value added in different service sectors, weighted by their respective values in 1980 . Prior to 1973, the same calculation was made on indices based on 1975. Also for the United Kingdom, the volume of manufactures, mining and quarrying and services aggregates were linked to 1975-based equivalent series (rebased on 1980). The source for the UK petroleum output value (Table 2.2, Series DIEY) and volume (Table 2.4, Series DVIP) rebased on 1980, is cSO 1989; prior to 1976, CSO 1983 (Table 2.3). The volume of total GDP taken from OECD, National Accounts Volume II, Table 1 - rebased as an index $1980=100$. 


\section{References}

Andresen, S. (1983): "Asymmetric Sector Growth in a Small, Open Economy: The Case of Norway and North Sea Oil", Master of Arts Degree Project submitted to Simon Fraser University.

Arndt, S. (1988): "Trade of Exchange Rates in a Diversified Economy", University of California, Santa Cruz, Department of Economics Working Paper No. 170 (February).

Bank of England (1982): "North Sea Oil and Gas - Costs and Benefits", Quarterly Bulletin, Vol. 22, No. 1 (March), pp. 56-73.

Barker, T. and V. Braclovsky (1981): 0il or Industry, Academic Press, London.

Bean, C. (1987): "The Impact of North Sea Oil" in The Performance of the British Economy, ed. by $R$. Dornbusch and R. Layard, Clarendon Press (Oxford).

Begg, D. (1982): The Rational Expectations Revolution, Oxford: Philip Alan. Bernanke, B. (1986): "Alternative Explanations of the Money-Income Correlation", in Carneige-Rochester Conference Series on Public Policy, Vol. 25 , pp. 49-99.

Bjerkholt, 0 . et al. (1981): "Using the $0 i 1$ and Gas Revenues: the Norwegian Case", Chapter 7 in $0 i 1$ or Industry, op. cit., pp. 171-184.

Blanchard, 0 . and $M$. Watson (1986): "Are Business Cycles All Alike?" in R.J. Gordon (ed.), The American Business Cycle: Continuity and Change, (Chicago, University of Chicago Press). 
Bond, M. and A. Knobl (1982): "Some Implications of North Sea 0il for the UK Economy" IMF Staff Papers, Vo1. 29, pp. 363-397.

Bruno, M. and J. Sachs (1982): "Input Price Shocks and the slowdown in Economic Growth: the Case of UK Manufacturing ", Review of Economic Studies, Vol. 49 , pp. 679-705.

Buiter, W. and D. Purvis (1983): "Oil, Disinflation and Export Competitiveness: A Model of the 'Dutch Disease'", in J. Bhandari and B. Putnam, eds., Economic Interdependence and Flexible Exchange Rates, Cambridge: MIT Press.

Buiter, W. and M. Miller (1982): "The Thatcher Experiment: the First Two Years", Brookings Papers on Economic Activity, Vol. 2, pp. 315-380.

Buiter, W. and M. Miller (1983): "Changing the Rules: Economic Consequences of the Thatcher Regime", Brookings Papers on Economic Activity, Vol. 2, pp. $305-365$.

Cappelen, A. et al. (1985): "Oil Revenues and the Norwegian Economy in the Seventies", in Macroeconomic Prospects for a Small 0il Exporting Economy, pp. 35-62.

Chrystal, K.A. (1984): "Dutch Disease or Monetarist Medicine? The British Economy under Mrs. Thatcher", Federal Reserve Bank of St. Louis, Economic Review, Vol. 66, pp. 27-37.

Cooley, T. and S. LeRoy (1985): "Atheoretical Macroeconomics: A Critique", Journal of Monetary Economics, Vol. 16, pp. 283-308.

Corden, W. (1981): "The Exchange Rate, Monetary Policy and North Sea 0il: the Economic Theory of the Squeeze on Tradables", Oxford Economic Papers, Vol. 33 (July supplement), pp. 23-46.

Corden, W. (1984): "Booming Sector and Dutch Disease Economics", Oxford Economic Papers, Vol. 36, pp. 359-380. 
Corden, W. and J. Neary (1982): "Booming Sector and De-industrialisation in a Small Open Economy", Economic Journal, Vo1. 92, pp. 825-848.

Driehuis, W. (1986): "Unemployment in the Netherlands", Economica, Vol. 53, pp. 297-312.

Eastwood, R. and A. Venables (1982): "The Macroeconomic Implications of a Resource Discovery in an Open Economy", Economic Journal, Vol. 92, pp. 285-299.

Ellman, M. (1981): "Natural Gas, Restructuring and Re-industrialisation: the Dutch Experience of Industrial Policy", Chapter 6 in 0il or Industry, pp. 149-166.

Engle, R. and C. Granger (1987): "Co-integration and Error Correction: Representation, Estimation, and Testing", Econometrica, Vol. 55, pp. 251-276.

Forsyth, P. (1986): "Booming Sectors and Structural Change in Australia and Britain: a Comparison", Chapter 6 in Natural Resources and the Macroeconomy, pp. 251-284.

Forsyth, P. and J. Kay (1980): "The Economic Implications of North Sea Oil Revenues", Fiscal Studies, Vol. 1, pp. 1-28.

Forsyth, P. and J. Kay (1981): "Oil Revenues and Manufacturing Output", Fiscal Studies, Vo1. 2, pp. 9-17.

Granger, C. and P. Newbold (1974): "Spurious Regressions in Econometrics", Journal of Econometrics, Vo1. 26, pp. 1045-1066.

Granger, C. and A. Weiss (1983): "Time Series Analysis of Error Correction Models", in S. Karlin et al. (eds.), Studies in Econometric Time-Series and Multivariate Statistics, New York: Academic Press.

Hakkio, C. and M. Rush (1987): "Market Efficiency and Cointegration", Federal Reserve Bank of Kansas City Working Paper No. 87-05 (September). 
Hendry, D. and G. Mizon (1978): "Serial Correlation as a Convenient Simplification, Not a Nuisance: a Comment on a study of the Demand for Money by the Bank of England", Economic Journal, Vol. 88, pp. 549-563.

Hendry, D. (1986): "Econometric Modelling with Cointegrated Variables: An Overview", Oxford Bulletin of Economics and Statistics, Vol. 48, pp. 201-211.

Kaldoe, N. (1981): "The Energy Issues", Chapter 1 in 0 il or Industry, pp. 3-9.

Kamas, L. (1986): "Dutch Disease Economies and the Colombian Export Boom", World Development, Vol. 14, pp. 1177-1198.

Kremers, J. (1986): "The Dutch Disease in the Netherlands" in Natural Resources and the Macroeconomy, pp. 96-141.

Laney, L. (1982): "How Contagious is 'Dutch Disease'?", Federal Reserve Bank of Dallas, Economic Review (March); pp. 3-12.

Meese, R, and K. Rogoff (1986): "Empirical Exchange Rate Models of the Seventies: Do They Fit Out-of-Sample?" Journal of International Economics, Vol. 14 (February), pp. 3-24.

Neary, J. and S. Van Wijnbergen (1986a): eds., Natural Resources and the Macroeconomy, Cambridge: MIT Press.

Neary, J. and S. Van Wijnbergen (1986b): "Introduction", in Natural Resources and the Macroeconomy, pp. 1-11.

Neary, J. and S. Van Wijnbergen (1986c): "Natural Resources and the Macroeconomy: A Theoretical Framework", Chapter 1 in Natural Resources and the Macroeconomy, pp. 13-45.

Neary, J.P. and S. Van Wijnbergen (1984): "Can Higher Oil Revenues Lead to a Recession? A comment on Eastwood and Venables", Economic Journal, Vol. 94, pp. 390-95. 
Nelson, C. and C. Plosser (1982): "Trends and Random Walks in Macroeconomic Time Series", Journal of Monetary Economics, Vol. 10, pp. 139-162.

Niehans, J. (1981): "The Appreciation of Sterling - Causes, Effects, Policies", SSRC Money Study Group Discussion Paper (February).

OECD (1978): OECD Economic Surveys 1977-1978 Netherlands, Paris.

OECD (1983): OECD Economic Surveys 1982-1983 Netherlands, Paris.

OECD (1983): OECD Economic Surveys 1982-1983 Norway, Paris.

OECD (1987): OECD Economic Surveys 1986-1987 Norway, Paris.

Phillips, P. (1985): "Understanding Spurious Regressions in Econometrics", Cowles Foundation Discussion Paper, 757.

Schmidt, R. (1989): "Natural Resources and Regional Growth", Federal Reserve Bank of San Francisco Economic Review, No. 4 (Fall), pp. 3-19.

Sheffrin, S. and T. Russell (1984): "Sterling and Oil Discoveries: The Mystery of Nonappreciation", Journal of International Money and Finance, Vol. 3, pp. 311-326.

Sims, C. (1980): "Macroeconomics and Reality", Econometrica, Vol. 48 (January), pp. 1-48.

Snape, R. (1977): "Effects of Mineral Development on the Economy". The Australian Journal of Agricultural Economics, Vol. 21, pp. 147-156.

Walsh, C. (1987): "Monetary Targetry and Inflation: 1976-1984", Federal Reserve Bank of San Francisco Economic Review, Winter, pp. 5-15.

Van Wijnbergen, Sweder (1984): "The 'Dutch Disease': A Disease After All?", The Economic Journal, Vol. 94 , pp. 41-55. 